\title{
COTTON IRRIGATION SCHEDULING USING A CROP GROWTH MODEL AND FAO-56 METHODS: FIELD AND SIMULATION STUDIES
}

\author{
K. R. Thorp, D. J. Hunsaker, K. F. Bronson, P. Andrade-Sanchez, E. M. Barnes
}

\begin{abstract}
Crop growth simulation models can address a variety of agricultural problems, but their use to directly assist in-season irrigation management decisions is less common. Confidence in model reliability can be increased if models are shown to provide improved in-season management recommendations, which are explicitly tested in the field. The objective of this study was to compare the CSM-CROPGRO-Cotton model (with recently updated ET routines) to a well-tested FAO56 irrigation scheduling spreadsheet by (1) using both tools to schedule cotton irrigation during 2014 and 2015 in central Arizona and (2) conducting a post-hoc simulation study to further compare outputs from these tools. Two replications of each irrigation scheduling treatment and a water-stressed treatment were established on a 2.6 ha field. Irrigation schedules were developed on a weekly basis and administered via an overhead lateral-move sprinkler irrigation system. Neutron moisture meters were used weekly to estimate soil moisture status and crop water use, and destructive plant samples were routinely collected to estimate cotton leaf area index (LAI) and canopy weight. Cotton yield was estimated using two mechanical cotton pickers with differing capabilities: (1) a two-row picker that facilitated manual collection of yield samples from $32 \mathrm{~m}^{2}$ areas and (2) a four-row picker equipped with a sensor-based cotton yield monitoring system. In addition to statistical testing of field data via mixed models, the data were used for post-hoc reparameterization and fine-tuning of the irrigation scheduling tools. Post-hoc simulations were conducted to compare measured and simulated evapotranspiration, crop coefficients, root zone soil moisture depletion, cotton growth metrics, and yield for each irrigation treatment. While total seasonal irrigation amounts were similar among the two scheduling tools, the crop model recommended more water during anthesis and less during the early season, which led to higher cotton fiber yield in both seasons $(p<0.05)$. The tools calculated cumulative evapotranspiration similarly, with root mean squared errors (RMSEs) less than 13\%; however, FAO56 crop coefficient $\left(K_{c}\right)$ plots demonstrated subtle differences in daily evapotranspiration calculations. Root zone soil moisture depletion was better calculated by CSM-CROPGRO-Cotton, perhaps due to its more complex soil profile simulation; however, RMSEs for depletion always exceeded 20\% for both tools and reached 149\% for the FAO-56 spreadsheet in 2014. CSM-CROPGRO-Cotton simulated cotton LAI, canopy weight, canopy height, and yield with RMSEs less than 21\%, while the FAO-56 spreadsheet had no capability for such outputs. Through field verification and thorough post-hoc data analysis, the results demonstrated that the CSM-CROPGRO-Cotton model with updated FAO-56 ET routines could match or exceed the accuracy and capability of an FAO-56 spreadsheet tool for cotton water use calculations and irrigation scheduling.
\end{abstract}

Keywords. Cottonseed, Crop coefficient, Decision support, Depletion, Evapotranspiration, Fiber, Management, Simulation, Soil moisture, Yield.

$\mathrm{A}$ mong myriad potential uses for crop growth simulation models (Boote et al., 1996), their use as an in-season aid for irrigation management decisions remains elusive. A notable exception was the pilot

Submitted for review in March 2016 as manuscript number NRES 12323; approved for publication as part of the "Crop Modeling and Decision Support for Optimizing Use of Limited Water" special collection by the Natural Resources \& Environmental Systems Community of ASABE in May 2017.

Mention of company or trade names is for description only and does not imply endorsement by the USDA. The USDA is an equal opportunity provider and employer.

The authors are Kelly R. Thorp, ASABE Member, Research Agricultural Engineer, Douglas J. Hunsaker, ASABE Member, Research Agricultural Engineer, and Kevin F. Bronson, Research Soil Scientist, USDA-ARS Arid Land Agricultural Research Center, Maricopa, Arizona; Pedro Andrade-Sanchez, ASABE Member, Associate Professor, Maricopa Agricultural Center, University of Arizona, Maricopa, Arizona; Edward M. Barnes, ASABE Member, Agricultural Research Director, Cotton Incorporated, Cary, North Carolina. Corresponding author: Kelly R. Thorp, USDA-ARS, 21881 N. Cardon Lane, Maricopa, AZ 85138; phone: 520-316-6375; e-mail: kelly.thorp@ars.usda.gov. test of the GOSSYM cotton simulation model and accompanying CrOp MAnagement eXpert system (COMAX) on 170 commercial farms across the U.S. Cotton Belt in 1988 (McKinion et al., 1989). More recently, the HydroLOGIC irrigation management system, which incorporated the OZCOT cotton simulation model, was tested during eleven on-farm experiments in Australia (Richards et al., 2008). Surprisingly, even rarer are reports of research agronomists using crop growth models to schedule in-season irrigation for field experiments on research stations. As one example, Suleiman et al. (2007) used the CSM-CROPGRO-Cotton model to schedule irrigation for cotton in Georgia and analyzed the experimental results using FAO-56 water balance methods (Allen et al., 1998). More routinely, crop growth models are used for post-hoc analysis of data from past field experiments, which culminate as an effort in model evaluation (Farahani et al., 2009; Guerra et al., 2004; Modala et al., 2015; Thorp et al., 2014b). Once evaluated, models are often applied as simulation tools to address a variety of research questions related to 
irrigation management (Baumhardt et al., 2009; Cammarano et al., 2012; DeJonge et al., 2007; Kisekka et al., 2016; McCarthey et al., 2014; Nair et al., 2013), crop water use (Droogers, 2000), or regional water management issues (Guerra et al., 2007; Yang et al., 2010). Use of models in this way can extend knowledge beyond the findings of field research, but the efforts certainly embody an exercise in extrapolation, with associated limiting assumptions. Caution must be exercised in the interpretation of these results, because error in model formulation and parameterization leads to simulations that depart from reality. On the other hand, by keeping crop growth modeling efforts routinely connected to in-season field management activities, model development can proceed in a direction that ensures appropriate in-season irrigation management decisions and potentially real-time feedback control of irrigation systems (McCarthy et al., 2013). Simultaneously, model improvements that result from a close marriage of modeling and field management activities improve confidence in the use of models for various other purposes.

In the past decades, evapotranspiration (ET) researchers have developed standardized approaches for calculating crop water use and irrigation requirements (Jensen et al., 2016). The efforts have led to standard methods for calculation of ET from both grass $\left(\mathrm{ET}_{o}\right)$ and alfalfa $\left(\mathrm{ET}_{r}\right)$ reference surfaces (Walter et al., 2005), which are now used by many meteorological networks around the world. In addition, crop coefficient $\left(K_{c}\right)$ methods for calculating actual crop ET from reference ET have been adopted by the Food and Agricultural Organization (FAO) of the United Nations (FAO-56; Allen et al., 1998) and used for irrigation planning and management worldwide. By using $\mathrm{ET}_{o}$ or $\mathrm{ET}_{r}$ with the FAO-56 dual $K_{c}$ approach, soil water evaporation and plant transpiration can be independently estimated on a daily basis, and a simple daily soil water balance computation enables calculations of water stress effects on ET in water-limited conditions. In central Arizona, research at the Maricopa Agricultural Center (MAC) has developed FAO-56 approaches for irrigation management in alfalfa (Medicago sativa (L.) Lew; Hunsaker et al., 2002), camelina (Camelina sativa (L.) Crantz; Hunsaker et al., 2013), upland cotton (Gossypium hirsutum L.; Hunsaker et al., 2005a, 2015), guayule (Parthenium argentatum (A.) Gray; Hunsaker and Elshikha, 2017), and wheat (Triticum aestivium L.; Hunsaker et al., 2005b, 2007a, 2007b). These efforts resulted in the development of an FAO-56 irrigation scheduling spreadsheet that is now well-tested for a variety of crops at MAC and used routinely to manage irrigation for many field research activities at the station. However, a main limitation of the FAO-56 approach is the use of a fixed, time-based crop coefficient curve, which is specified from values in FAO-56 tables and remains inflexible to changes in plant nutrient status, plant density, growing degree day accumulation, pest pressure, and other sources of crop growth variability. As one approach to solve this problem, multispectral vegetation indices have been developed to estimate FAO-56 crop coefficients in-season (Bausch and Neale, 1989; Hunsaker et al., 2005a, 2005b, 2007a, 2007b). Alternatively, as explored herein, crop coefficient curves can be simulated by integrating FAO-56 methods with crop growth models. Due to the extensive prior testing of FAO-56 methods at MAC, FAO-56 can also serve as an appropriate benchmark for crop model improvement and development as a tool for irrigation management.

Preliminary efforts to schedule irrigation for Arizona cotton using a crop growth model were commenced during the 2007 cotton growing season at MAC. The Cropping System Model (CSM; Jones et al., 2003), as distributed with the Decision Support System for Agrotechnology Transfer (DSSAT; www.dssat.net), was used for the effort. Of the several available ET routines in DSSAT-CSM, the one based on FAO-56 was selected, so that the crop model could be better compared to an existing FAO-56 irrigation scheduling spreadsheet (Hunsaker et al., 2005a). Results from the 2007 study remain unpublished because the DSSAT-CSM irrigation recommendation lagged behind the FAO-56 spreadsheet recommendation. This led to several decisions based on experience and intuition to apply more water than DSSAT-CSM recommended, thereby salvaging the crop from severe stress. Nevertheless, the FAO-56 spreadsheet treatment yielded $12 \%$ higher than the DSSAT-CSM treatment. Other research has confirmed, clarified, and improved on the deviations between DSSAT-CSM and FAO-56 methods. Sau et al. (2004) determined that the FAO-56-based ET routine in DSSAT-CSM underestimated soybean ET. Thorp et al. (2010) evaluated DSSAT-CSM for Arizona wheat and reported difficulty in simulating crop growth and water use unless the model's current crop coefficient parameter (EORATIO) was set to an unreasonably high value of 1.8. Independently, DeJonge et al. (2012) developed a crop coefficient equation for the CSM-CERES-Maize model that better followed the FAO-56 protocol and led to better simulations of maize (Zea mays L.) ET under both full and limited irrigation in Colorado. Thorp et al. (2014b) modified DSSAT-CSM to include the DeJonge et al. (2012) crop coefficient equation and the Walter et al. (2005) standard algorithm for grass reference $\mathrm{ET}_{o}$ calculations. The updates improved the simulation of seasonal cotton ET in Arizona, which was underestimated by $15 \%$ with the model's original FAO-56 approach. An error in the model's wind speed adjustment equation for calculating $\mathrm{ET}_{o}$ was later identified for cases of non-standard wind measurement height (e.g., Arizona meteorological network stations measure wind speed at $3 \mathrm{~m}$ rather than the standard $2 \mathrm{~m}$ height), which was circumvented by inclusion of the Walter et al. (2005) standard $\mathrm{ET}_{o}$ algorithm (DeJonge and Thorp, 2017). Thorp et al. (2015) used the updated DSSAT-CSM model to analyze site-specific yield and water use for Arizona cotton, obtaining more reasonable crop coefficient parameters $($ EORATIO $=1.0$ to 1.5) with an iterative optimization technique. DeJonge and Thorp (2017) further modified DSSAT-CSM to incorporate a dual FAO-56 crop coefficient approach, which brought the model more fully in compliance with FAO-56 methods. Efforts to improve DSSAT-CSM in these ways were, in part, spurred by failed attempts at using the model for in-season cotton irrigation management in 2007 in Arizona. Because the FAO-56 spreadsheet method had demonstrated prior success (Hunsaker et al., 2005a), it was chosen as a benchmark for crop model improvements.

The main objective of this study was to compare DSSATCSM, including an updated FAO-56 ET routine (DeJonge and Thorp, 2017), with a well-tested FAO-56 spreadsheet 
method (Hunsaker et al., 2005a) for in-season cotton irrigation scheduling in central Arizona. While both irrigation scheduling tools incorporated FAO-56 dual crop coefficient procedures and the Walter et al. (2005) standard algorithm for $\mathrm{ET}_{o}$ calculations, they used different approaches to specify crop coefficients, calculate soil water processes, and consider effects of crop development and growth on water balances. Specific objectives were to (1) conduct a field investigation using these decision tools to schedule irrigations during two Arizona cotton growing seasons and (2) conduct a post-hoc simulation study to further evaluate and compare the outputs of the tools.

\section{Materials ANd Methods FIELD EXPERIMENTS}

Cotton irrigation scheduling experiments were conducted using an overhead lateral-move sprinkler irrigation system at the University of Arizona's Maricopa Agricultural Center (MAC) near Maricopa, Arizona $\left(33.079^{\circ} \mathrm{N}, 111.977^{\circ} \mathrm{W}\right.$, $360 \mathrm{~m}$ above sea level) during the 2014 and 2015 growing seasons. The soil texture at the site was predominantly sandy loam and sandy clay loam, as determined by textural analysis of soil samples. The environment in central Arizona is arid and hot, with maximum daily air temperatures regularly exceeding $38^{\circ} \mathrm{C}$ in July and August. Growing season precipitation from April through September amounted to 140 and $87 \mathrm{~mm}$ in 2014 and 2015, respectively. In comparison, grass reference $\mathrm{ET}_{o}$ during the same period was 1310 and $1290 \mathrm{~mm}$ in 2014 and 2015, respectively. Thus, cotton production in central Arizona requires irrigation.

The experimental design included two replications of three irrigation management treatments (fig. 1), including (1) the FAO treatment (FAO) with irrigation management determined by a locally adapted and well-tested FAO-56 ETbased irrigation scheduling spreadsheet (Hunsaker et al., 2005a), (2) the crop model treatment (CMD) with irrigation management determined by the DSSAT CSM-CROPGROCotton simulation model, previously calibrated for central Arizona conditions (Thorp et al., 2014b), and (3) a waterstressed treatment (WST) that followed the schedule for the FAO treatment but with approximately a $30 \%$ reduction in seasonal irrigation rate by using smaller nozzles on the irrigation machine during reproductive development. Each treatment plot was $24.5 \mathrm{~m}$ wide (24 cotton rows) and $174.2 \mathrm{~m}$ long (the full travel distance of the lateral-move sprinkler system), providing 0.43 ha areas for uniform irrigation management. In the second year, one of the WST treatments was relocated to an area with more available space. The remainder of the field was planted to cotton but designated to other experimental purposes (fig. 1). Upland cotton (Gossypium hirsutum L., cv. 'Deltapine 1044B2RF') was planted in raised beds on 2 May 2014 [day of year (DOY) 122] and 29 April 2015 (DOY 119) with a row spacing of $1.02 \mathrm{~m}$. Average measured post-emergence plant densities were 7.5 plants $\mathrm{m}^{-2}$ in 2014 and 10.0 plants $\mathrm{m}^{-2}$ in 2015. Based on pre-plant soil sampling for soil nitrate concentration, liquid urea ammonium nitrate (UAN 32-0-0) was uniformly applied in three split applications, amounting to seasonal nitrogen $(\mathrm{N})$ application rates of $180 \mathrm{~kg} \mathrm{~N} \mathrm{ha}^{-1}$ in 2014 and $131 \mathrm{~kg} \mathrm{~N} \mathrm{ha}^{-1}$ in 2015 (Bronson et al., 2015). The first two splits were injected with a tractor-based liquid $\mathrm{N}$ applicator, while the final split was dribbled on at anthesis (i.e., flowering) using a high-clearance sprayer. Fertilizer application dates were 27 May (DOY 147), 17 June (DOY 168), and 8 July (DOY 189) in 2014 and 9 June (DOY 160), 24 June (DOY 175), and 7 July (DOY 188) in 2015.

In the months prior to the 2014 field experiment, a new

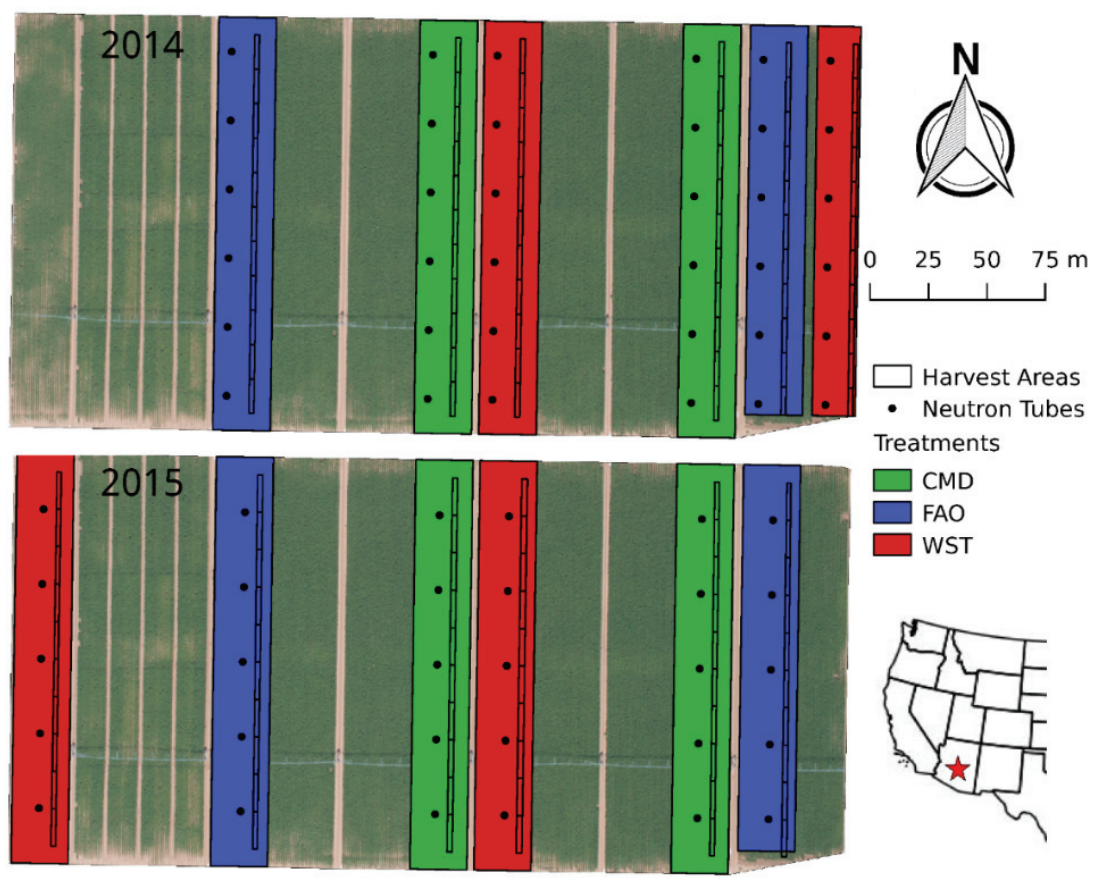

Figure 1. Maps of cotton irrigation scheduling experiments conducted at Maricopa, Arizona, in 2014 and 2015 . The spatial locations are provided for the harvest areas for bagged yield samples, access tubes for neutron moisture meters, and experimental treatments with irrigation managed by the CSM-CROPGRO-Cotton model (CMD), the FAO-56 spreadsheet (FAO), and a water-stressed treatment (WST). 
six-span overhead lateral-move sprinkler irrigation system (Zimmatic, Lindsay Corp., Omaha, Neb.) was installed at the field site. Designed to irrigate a 5.9 ha area, the system traveled $174 \mathrm{~m}$ while pumping water at $50 \mathrm{~L} \mathrm{~s}^{-1}$ from an existing irrigation canal on the MAC farm. Drop hoses were positioned centrally between cotton rows at $1.02 \mathrm{~m}$ spacing with the nozzle assembly positioned approximately $50 \mathrm{~cm}$ above the ground. Spray plates were used for cotton germination and emergence. After adequate stand establishment, drag hoses were added to deliver water directly into the furrows between raised cotton beds. The machine was equipped with nozzles (\#11, Senninger, Clermont, Fla.) with a flow rate of $0.13 \mathrm{~L} \mathrm{~s}^{-1}$, preceded by a $41.4 \mathrm{kPa}$ pressure regulator. To manage the WST treatment, nozzles with smaller orifices (\#9, Senninger, Clermont, Fla.) were used to reduce the nozzle flow rate to $0.1 \mathrm{~L} \mathrm{~s}^{-1}$. The switch to smaller nozzles for WST plots occurred on 30 May 2014 (DOY 150) and 8 July 2015 (DOY 189). Irrigation application rates $\left(\mathrm{mm} \mathrm{ha}^{-1}\right)$ for different speed settings on the irrigation machine were obtained from an engineering design table provided by the manufacturer. Because the machine was newly constructed in the spring of 2014, efforts to verify the accuracy of this rate table were undertaken. Two calibrated flowmeters were added to the main intake pipe in 2014. In addition, the lateral ground speed at several speed settings was measured with a stopwatch, and nozzles flow rates were verified by timed volume measurements. After several iterations of these efforts, it was determined that the manufacturer's engineering design table overestimated the actual irrigation rate by $18 \%$. As a temporary solution to better match the manufacturer's rates, nozzles with a larger orifice (\#12, Senninger, Clermont, Fla.) were installed for all but the WST treatments on 9 July 2015 (DOY 190). Use of inaccurate irrigation application rates certainly impacted the in-season calculations of the irrigation scheduling tools and led to reduced irrigation amounts and reduced cotton yield, particularly in 2014.

The ground speed of the irrigation machine was controlled based on a speed setting (1\% to $100 \%)$ on the main control panel. Typical speed settings were $100 \%(38.4 \mathrm{~mm}$ $\left.\mathrm{s}^{-1}\right), 50 \%\left(19.4 \mathrm{~mm} \mathrm{~s}^{-1}\right)$, and $25 \%\left(9.7 \mathrm{~mm} \mathrm{~s}^{-1}\right)$, which allowed the machine to traverse the field in approximately 1.5 , 3.0 , and $6.0 \mathrm{~h}$ and apply $4.0,8.0$, and $15.9 \mathrm{~mm} \mathrm{ha}^{-1}$ of water, respectively, with \#12 nozzles. The irrigation depths were based on measurements of system travel speed at different speed settings (\%) and manufacturer's specifications of nozzle flow rates at $41.4 \mathrm{kPa}$, which were verified during machine calibration efforts. Up to 20 passes at $100 \%$ speed were required per week during peak irrigation demand, typically divided among two or three consecutive days. Application rates $\left(\mathrm{mm} \mathrm{ha}^{-1}\right)$ per pass of the irrigation system depended on the speed setting and the nozzle size. Irrigation schedules were determined on Monday or Tuesday of each week, so water could be ordered for timely delivery to the field site via on-farm canals. The primary irrigation time was during daytime hours on Wednesday through Friday each week. Irrigation on Tuesday afternoon or Saturday morning was also conducted as needed. Monday and Tuesday were reserved as "dry days" for field entry and data collection. If the CMD scheduling approach recommended more or less irrigation than the FAO approach, irrigation treatments were differentiated by manually switching off nozzles during the final irrigation events of the week.

\section{Field Measurements}

After crop emergence, steel access tubes ( $5 \mathrm{~cm}$ diameter) for neutron moisture meters were installed at 36 locations in 2014 (six locations per treatment plot) and 30 locations in 2015 (five locations per treatment plot) (fig. 1) using a tractor-mounted Giddings soil sampler (model 25-TS, Giddings Machine Co., Windsor, Colo.). Field-calibrated neutron moisture meters (model 503, Campbell Pacific Nuclear, Martinez, Cal.) were used to measure soil water content from 0.1 to $1.9 \mathrm{~m}$ in $0.2 \mathrm{~m}$ incremental depths at each access tube. The meters were deployed approximately 18 times per season on a weekly basis from early June to early October. Soil water content data were used to estimate ET between successive measurement events using the soil water balance approach described by Hunsaker et al. (2005a):

$$
\mathrm{ET}=\sum_{i=1}^{10}\left(D_{i, 1}-D_{i, n-1}\right)+\sum_{j=1}^{n-1}\left(R_{j}+I_{j}\right)-\mathrm{DS}
$$

where ET is the total evapotranspiration, DS is the total deep seepage occurring from the beginning of a given measurement day (denoted as day $j=1$ ) to the end of the day before the successive measurement date (denoted as day $j=n-1$ ), $D_{i, 1}$ and $D_{i, n-1}$ are respectively the water depth measurements at soil depth increment $i$ at the beginning of day 1 and at the end of day $n-1$, and $R_{j}$ and $I_{j}$ are respectively the precipitation and net irrigation depths received on day $j$. For the sake of practicality, soil water content measurements collected on the morning of day $n$ were used to approximate soil water content at the end of day $n-1$. Because the field was generally underirrigated, the DS term was assumed negligible for both growing seasons, which was supported by model simulations of DS less than $1 \%$ of water inputs. Runoff and runon were also negligible due to planting cotton on raised beds and manual establishment of furrow dikes. Estimates of $K_{c}$ were obtained by dividing the ET between successive neutron moisture meter measurements by the sum of daily grass reference $\mathrm{ET}_{o}$ over the same period:

$$
K_{c}=\mathrm{ET} / \sum_{j=1}^{n-1} \mathrm{ET}_{o j}
$$

Root zone soil moisture depletion $\left(D_{r}\right)$ was calculated from soil water content measurements using the following equation:

$$
D_{r}=1-\sum_{i=1}^{r}\left(D_{i}-D_{i, L L}\right) / \sum_{i=1}^{r}\left(D_{i, D U L}-D_{i, L L}\right)
$$

where $r$ is the root zone depth layer, $D_{i}$ is the water depth measurement at soil depth increment $i$, and $D_{i, D U L}$ and $D_{i, L L}$ are the water depth values at the drained upper limit and lower limit, respectively, at soil depth increment $i$, which were estimated from soil texture measurements and crop growth model calibration efforts, described below. The denominator of equation 3 is the total available water (TAW), 
as defined in FAO-56 (Allen et al., 1998). As required for these calculations, the temporal change in depth of the root zone was estimated from calculations by the FAO-56 spreadsheet and CSM-CROPGRO-Cotton. Generally, the calculations of root zone soil moisture depletion ("depletion" hereafter) were sensitive to the soil water content measurements and estimates for drained upper limit, lower limit, and rooting depth. Thus, uncertainty in this information contributed to uncertainty in the depletion calculations. These calculations of ET, $K_{c}$, and $D_{r}$ were treated as "measurements" for purposes of comparison to outputs from the irrigation scheduling tools.

During the installation of neutron access tubes in both growing seasons, soil samples in $0.3 \mathrm{~m}$ increments to a depth of $1.8 \mathrm{~m}$ were collected (fig. 1). To quantify soil texture, samples were analyzed for particle size fraction in the laboratory using the Bouyoucos hydrometer method (Gee and Bauder, 1986). The Rosetta pedotransfer functions (Schaap et al., 2001) were used to calculate soil bulk density, saturated hydraulic conductivity, saturated soil water content (porosity), drained upper limit (field capacity), and lower limit (wilting point) based on soil texture data at each depth and location.

Cotton plants were destructively sampled at two locations within each treatment plot on three occasions in 2014 [24 June (DOY 175), 22 July (DOY 203), and 18 August (DOY 230)] and on seven occasions in 2015 [10 June (DOY 161), 23 June (DOY 174), 7 July (DOY 188), 22 July (DOY 203), 4 August (DOY 216), 17 August (DOY 229), and 31 August (DOY 243)]. Plants in two $0.5 \mathrm{~m}$ row lengths at each location were cut at the soil surface and bagged. Within $24 \mathrm{~h}$, plants were dissected into component plant parts, including leaves, stems, and reproductive structures. The total leaf area of each sample was measured on an area meter (model 3100, Li-Cor, Lincoln, Neb.) and used to calculate leaf area index (LAI). Samples were oven-dried at $65^{\circ} \mathrm{C}$ with ventilation until constant weight was achieved. Canopy dry weight per hectare ("canopy weight" hereafter) was calculated from oven-dried biomass weight measurements.

Cotton canopy height was measured on a biweekly basis in 2014 and on a weekly basis in 2015 near the locations of the neutron access tubes. In 2014, canopy height was measured on six occasions from 3 June (DOY 154) to 12 August (DOY 224). In 2015, canopy height was measured on fifteen occasions from 2 June (DOY 153) to 8 September (DOY 251).

In 2014, eleven zones were delineated in each treatment plot for cotton yield measurements, each two rows by $14.5 \mathrm{~m}$. In 2015, ten harvest zones were delineated per treatment plot, each two rows by $16.0 \mathrm{~m}$ (fig. 1). Within each harvest zone, cotton was machine-harvested with a two-row picker on 12 November 2014 (DOY 316) and 17 November 2015 (DOY 321). Cotton yield samples from each harvest zone were bagged and weighed separately in the field. Two subsamples from each bag were obtained for ginning and for moisture analysis. Moisture samples were stored in sealed plastic bags until transfer to drying ovens, with wet and dry sample weights used to calculate moisture content. Samples for ginning were stored in paper sacks and transferred to the MAC ginning facility to separate fiber, cottonseed, and trash. Moisture content and fiber turnout percentages were used to correct the original bulk cotton sample weights to dry fiber and cottonseed weights. Dry seed cotton yield was computed as the sum of the dry fiber and cottonseed weights on an area basis $\left(\mathrm{kg} \mathrm{ha}^{-1}\right)$.

From the remaining cotton rows in each plot, site-specific yield measurements were obtained using a cotton yield monitoring system with instrumentation installed on the two outside chutes of a four-row cotton picker on 19 November 2014 (DOY 323) and 23 November 2015 (DOY 327). The yield monitoring system consisted of a differential-correction global positioning system (DGPS), an in-cab computer display, and optical flow sensors. Standard calibration procedures were performed prior to harvesting based on the manufacturer's recommendations. The yield monitoring system was used to map cotton yield on four cotton rows per treatment plot in 2014 and on twelve cotton rows per treatment plot in 2015 with a spatial resolution of approximately two yield measurements per meter. The yield monitoring system provided comma-delimited data files, which were loaded into a geographic information system (Quantum GIS; www.qgis.org) for visualization of spatial yield variability, intersection of data points with plot areas, and calculation of mean cotton yield per plot.

Hierarchical linear mixed modeling was used to assess differences in field measurements among the three irrigation treatments. Irrigation treatment was modeled as a fixed effect, and treatment block was modeled as a random effect. Hierarchical tests required fitting random effects both with and without the fixed effects. Likelihood ratio tests were used to compare the two hierarchical models, which showed whether the measurement was different among irrigation treatments. Tukey multiple comparisons tests were used to contrast the treatment means. Linear mixed models were computed using the "Ime4" package within the R Project for Statistical Computing software (http://r-project.org).

\section{FAO-56 SPREADSHEET}

To manage irrigation for the FAO treatment, an FAO-56 irrigation scheduling spreadsheet was used, which was previously developed, parameterized, and field-tested for cotton irrigation scheduling in central Arizona (Hunsaker et al., 2005a). The spreadsheet incorporated equations for FAO-56 dual crop coefficient ET estimation procedures, calculated a simple daily water balance of the root zone, and used a fixed basal crop coefficient $\left(K_{c b}\right)$ curve based on days after cotton planting as defined in FAO-56 (Allen et al., 1998; Jensen et al., 2016). Required daily meteorological information, including maximum and minimum air temperature, dew point temperature, wind speed, solar irradiance, and precipitation, were obtained from an Arizona Meteorological Network (AZMET; http://ag.arizona.edu/azmet/) station approximately $1.2 \mathrm{~km}$ from the field site and used to calculate $\mathrm{ET}_{o}$ via standardized methods (Walter et al., 2005). For in-season irrigation scheduling, predictions of $\mathrm{ET}_{o}$, minimum relative humidity, and wind speed at future times were estimated as the average value for a given DOY over the station's weather history from 1987 to present. To plan weekly irrigation events, the spreadsheet permitted manual entry and testing of potential irrigation schedules with quick updating of 
spreadsheet calculations. Based on its predicted depletion one week in advance, irrigation was scheduled to maintain less than $45 \%$ depletion of TAW between irrigation events. That is, $45 \%$ was the Management Allowed Depletion (MAD; Allen et al., 1998).

Following the field investigations, post-hoc analysis with the spreadsheet was undertaken to (1) improve its parameterization using data collected during the field trials and (2) update its calculations using better estimates for the irrigation rates actually applied. Maximum $K_{c b}$ was adjusted from 1.2 to 1.1 to improve agreement between measured and calculated ET (eq. 1). Maximum crop height was adjusted from 1.2 to $1.0 \mathrm{~m}$ to better match canopy height measurements. Maximum rooting depth was adjusted from 1.7 to $1.5 \mathrm{~m}$ based on water extraction patterns in the soil moisture measurements. Available soil water capacity was adjusted from 125 to $113 \mathrm{~mm} \mathrm{~m}^{-1}$ based on the texture analysis of soil samples at the field site. After these parameter adjustments, post-hoc recalculations of the irrigation schedules for the 2014 and 2015 seasons were conducted to assess updated irrigation management recommendations following two years of experience with the field site and irrigation system.

\section{CSM-CROPGRO-COTTON}

To manage irrigation for the CMD treatment, the DSSAT CSM-CROPGRO-Cotton simulation model was used, which was previously evaluated for cotton production in central Arizona at sites less than $3.0 \mathrm{~km}$ from the present field (Thorp et al., 2014b). The model uses mass balance principles to simulate carbon, nitrogen, and hydrologic processes and transformations that occur in a cropping system. Simulations of cotton development proceed through a series of stages based on photothermal unit accumulation from planting to harvest. Light interception is simulated based on an elliptical hedgerow canopy, and potential carbon assimilation is computed from leaf-level biochemistry equations with growth and maintenance respiration deducted. The model calculates stress effects from deficit soil water and soil $\mathrm{N}$ conditions, which further reduce the carbohydrate available for simulated plant growth. Assimilated carbon is partitioned to various plant parts, including leaves, stems, roots, bolls, and seed cotton (fiber + seed). CSM-CROPGRO-Cotton currently simulates seed cotton yield, rather than separating calculations for fiber and seed yield. Based on measured fiber and seed weights after ginning, simulated fiber and seed yields were calculated by multiplying the model's seed cotton yield output by 0.4 and 0.6 , respectively.

Water deficits are simulated when the potential demand for water lost through plant transpiration and soil water evaporation is higher than the amount of water supplied by the soil through the simulated root system. As reported by Thorp et al. (2014b) and DeJonge and Thorp (2017), the Walter et al. (2005) standard algorithm for $\mathrm{ET}_{o}$ and $\mathrm{ET}_{r}$ calculations was recently added to the model as an ET simulation option. The approach was implemented for $\mathrm{ET}_{o}$ computation in both growing seasons. In 2014, the single crop coefficient equation of DeJonge et al. (2012) was used to adjust $\mathrm{ET}_{o}$ to potential crop ET. Prior to the 2015 season, DeJonge and Thorp (2017) further updated the model to include a dual crop coefficient method with $K_{c b}$ estimated from model-simulated LAI. The latter dual crop coefficient approach was used for in-season irrigation scheduling in 2015 and for posthoc simulation analysis of both growing seasons. The model simulates a layered, one-dimensional soil profile with a tipping-bucket method for water redistribution and algorithms for calculating soil and plant $\mathrm{N}$ balances. Additional details about CSM-CROPGRO-Cotton can be found in Jones et al. (2003) and Thorp et al. (2014a, 2014b, 2015).

The main differences between CSM-CROPGRO-Cotton and the FAO-56 spreadsheet were that (1) the crop model used simulated LAI to dynamically adjust the $K_{c b}$ curve while the spreadsheet used a fixed, locally adapted $K_{c b}$ curve based on FAO-56 tables, (2) the crop model simulated the soil profile with ten uniquely parameterized layers while the spreadsheet considered only one soil layer, and (3) the crop model simulated effects of $\mathrm{N}$ deficit, planting density, and photothermal unit accumulation on plant growth while the spreadsheet did not consider any of these effects and did not calculate plant growth processes. Similarities of the two approaches included use of the FAO-56 dual crop coefficient procedures and the Walter et al. (2005) standard algorithm for $\mathrm{ET}_{o}$ calculations.

To use CSM-CROPGRO-Cotton for in-season irrigation scheduling, the simulations necessarily spanned both past and future times; therefore, a combination of past weather measurements and future weather predictions was required for full-season model simulations. A Python script (www.python.org) was developed to download meteorological data from AZMET and construct weather input files that included the current season's weather record thus far and historical weather data to predict future conditions. Required weather inputs were the same as those for the FAO-56 spreadsheet. Data from 1 January through yesterday were downloaded for the present growing season. Weather predictions for today through the season's end were iteratively assigned as the weather record for a given year in the station's weather history from 1987 to present. Thus, the model was run iteratively for 27 and 28 weather data sets in 2014 and 2015 , respectively, to test outcomes with different future weather predictions, all estimated from the station's weather history (i.e., 1987 through 2013 in the 2014 season and 1987 through 2014 in the 2015 season). In addition, 24 potential weekly irrigation schedules were simulated with an incremental irrigation rate equal to the application depth at the fastest speed of the irrigation machine. Thus, the first irrigation rate corresponded to one pass of the irrigation machine at $100 \%$ speed, and the 24 th irrigation rate corresponded to 24 passes of the irrigation machine at $100 \%$ speed. Incremental irrigation rates were distributed over Wednesday, Thursday, and Friday of the week. The model was run on Tuesday of each week. For each simulated weather record and irrigation schedule, soil moisture depletion within the simulated rooting depth was calculated from simulated soil water content. The irrigation schedule that averaged $45 \%$ depletion over all the weather records at the end of the following Tuesday was selected for application that week. In summary, the model was used to iteratively test irrigation management options as if future weather conditions for the present growing season were each of the possible options from 
the station's weather history, and the irrigation rate decision was based on maintaining an average of $45 \%$ simulated depletion (one week in advance of today) among the future weather possibilities.

Similar to the FAO-56 spreadsheet, post-hoc simulations with CSM-CROPGRO-Cotton were conducted to (1) improve its parameterization using data collected during the field trials and (2) update its calculations using better estimates for the irrigation rates actually applied. The model was parameterized to simulate all three experimental treatments: FAO, CMD, and WST. Because there were no measurements of soil water content prior to crop emergence, simulations were initiated on 1 January of each year to permit an initialization period for soil water contents and nutrient pools. As a baseline starting point, the initial soil water content in each soil layer was set to the average of soil water measurements collected during the succeeding growing season, and four months (January through April) of environmental and management data, including pre-plant irrigation, were simulated to initialize the soil water and nutrient state variables. All management inputs were specified as conducted during the field experiment, and weather files were created using AZMET data collected during 2014 and 2015. For preliminary simulations, the lower limit (SLLL), drained upper limit (SDUL), saturated soil water content (SSAT), saturated hydraulic conductivity (SSKS), and bulk density (SBDM) were specified from the results of soil texture analysis and Rosetta calculations (table 1), but SLLL and SDUL were further adjusted as discussed below. Initial soil organic carbon (SLOC) and electrical conductivity (SCEC) were based on the MAC farm soil descriptions of Post et al. (1988). Soil $\mathrm{pH}$ in water (SLHW) was obtained from a digital soil survey of the site. To improve ET simulations, the minimum $K_{c b}(\mathrm{KMIN})$, maximum $K_{c b}(\mathrm{KMAX})$, and shaping coefficient (SKC) were adjusted to $0.0,1.1$, and 0.65 , respectively (table 2). Crop development parameters (EM-FL, FL$\mathrm{SH}, \mathrm{FL}-\mathrm{SD}$, SD-PM, and FL-LF) were adjusted to improve agreement between measured and simulated crop development stages (table 2). The THRSH parameter was adjusted to 80 based on measurements of burr, seed, and fiber fractions from plant sampling efforts. To specify parameters that improved crop growth, water use, and soil water content simulations, an algorithm based on Sobol (1998) was used to sample a 26-dimensional parameter space that included (1) the SLLL in each of ten soil layers, (2) the SDUL in each of ten soil layers, (3) the root growth factor (SRGF) in the 30 to $45 \mathrm{~cm}$ soil layer, (4) a value used to calculate reduction in SRGF in successive soil layers to $150 \mathrm{~cm},(5)$ the maximum leaf photosynthetic rate (LFMAX), (6) the specific leaf area in standard growth conditions (SLAVR), (7) the maximum fraction of daily growth partitioned to bolls (XFRT), and (8) relative canopy height (RHGHT). A total of 90,000 parameter combinations were tested using iterative model simulations, managed by a Python script. For each parameter combination, simulation results were compared with data for the FAO, CMD, and WST treatments in both growing seasons, and root mean squared errors (RMSE) were calculated from measured and simulated data for soil water content, cumulative ET, LAI, canopy weight, canopy height, and seed cotton yield. After ranking each parameter set for each

Table 1. CSM-CROPGRO-Cotton soil parameterization for the 2014 and 2015 cotton experiments at Maricopa, Arizona. ${ }^{\text {[a] }}$

\begin{tabular}{|c|c|c|c|c|c|c|c|c|c|c|c|c|c|}
\hline $\begin{array}{l}\text { Depth } \\
(\mathrm{cm})\end{array}$ & $\begin{array}{c}\text { SLLL } \\
\text { Rosetta } \\
\left(\mathrm{cm} \mathrm{cm}^{-1}\right)\end{array}$ & $\begin{array}{c}\text { SLLL } \\
\text { Sobol } \\
\left(\mathrm{cm} \mathrm{cm}^{-1}\right)\end{array}$ & $\begin{array}{c}\text { SDUL } \\
\text { Rosetta } \\
\left(\mathrm{cm} \mathrm{cm}^{-1}\right)\end{array}$ & $\begin{array}{c}\text { SDUL } \\
\text { Sobol } \\
\left(\mathrm{cm} \mathrm{cm}^{-1}\right)\end{array}$ & $\begin{array}{c}\text { SSAT } \\
\text { Rosetta } \\
\left(\mathrm{cm} \mathrm{cm}^{-1}\right)\end{array}$ & $\begin{array}{l}\text { SRGF } \\
\text { Sobol }\end{array}$ & $\begin{array}{c}\text { SSKS } \\
\text { Rosetta } \\
\left(\mathrm{cm} \mathrm{h}^{-1}\right) \\
\end{array}$ & $\begin{array}{l}\text { SBDM } \\
\text { Rosetta } \\
\left(\mathrm{g} \mathrm{cm}^{-3}\right)\end{array}$ & $\begin{array}{c}\text { SLOC } \\
(\%)\end{array}$ & $\begin{array}{c}\text { SLCL } \\
(\%)\end{array}$ & $\begin{array}{c}\text { SLSI } \\
(\%)\end{array}$ & SLHW & $\begin{array}{c}\text { SCEC } \\
\left(\mathrm{cmol} \mathrm{kg}^{-1}\right)\end{array}$ \\
\hline $0-5$ & 0.119 & 0.092 & 0.233 & 0.259 & 0.393 & 1.000 & 0.49 & 1.61 & 0.58 & 27.0 & 17.7 & 8.3 & 12.0 \\
\hline $5-15$ & 0.119 & 0.084 & 0.233 & 0.228 & 0.393 & 1.000 & 0.49 & 1.61 & 0.58 & 27.0 & 17.7 & 8.3 & 12.0 \\
\hline $15-30$ & 0.119 & 0.125 & 0.233 & 0.211 & 0.393 & 0.146 & 0.49 & 1.61 & 0.58 & 27.0 & 17.7 & 8.3 & 12.0 \\
\hline $30-45$ & 0.123 & 0.159 & 0.236 & 0.264 & 0.392 & 0.097 & 0.50 & 1.61 & 0.17 & 28.1 & 15.9 & 8.3 & 12.0 \\
\hline $45-60$ & 0.123 & 0.154 & 0.236 & 0.223 & 0.392 & 0.064 & 0.50 & 1.61 & 0.17 & 28.1 & 15.9 & 8.3 & 12.0 \\
\hline $60-90$ & 0.116 & 0.146 & 0.229 & 0.232 & 0.392 & 0.042 & 0.59 & 1.61 & 0.17 & 26.2 & 17.1 & 8.3 & 12.0 \\
\hline $90-120$ & 0.125 & 0.105 & 0.239 & 0.258 & 0.396 & 0.028 & 0.52 & 1.60 & 0.17 & 29.0 & 16.3 & 8.3 & 12.0 \\
\hline $120-150$ & 0.116 & 0.134 & 0.229 & 0.196 & 0.393 & 0.019 & 0.59 & 1.61 & 0.17 & 26.3 & 17.3 & 8.3 & 12.0 \\
\hline $150-180$ & 0.117 & 0.100 & 0.230 & 0.204 & 0.393 & 0.000 & 0.61 & 1.61 & 0.17 & 26.8 & 16.2 & 8.3 & 12.0 \\
\hline $180-210$ & 0.117 & 0.105 & 0.230 & 0.193 & 0.393 & 0.000 & 0.61 & 1.61 & 0.17 & 26.8 & 16.2 & 8.3 & 12.0 \\
\hline
\end{tabular}

[a] SLLL $=$ lower limit, SDUL $=$ drained upper limit, SSAT $=$ saturated soil water content, SRGF $=$ soil root growth factor, SSKS $=$ saturated hydraulic conductivity, $\mathrm{SBDM}=$ bulk density, $\mathrm{SLOC}=$ organic carbon content, $\mathrm{SLCL}=$ clay content, $\mathrm{SLSI}=$ silt content, $\mathrm{SLHW}=\mathrm{pH}$ in water, and $\mathrm{SCEC}=$ cation exchange capacity.

Table 2. CSM-CROPGRO-Cotton crop parameterization for the 2014 and 2015 cotton experiments at Maricopa, Arizona.

\begin{tabular}{lccc}
\hline & Parameter & Description & Value \\
\hline Cultivar parameters & EM-FL & Photothermal time between plant emergence and flower appearance & 45 \\
(COGRO046.SPE) & FL-SH & Photothermal time between first flower and first boll & 4 \\
& FL-SD & Photothermal time between first flower and first seed & 6 \\
& SD-PM & Photothermal time between first seed and physiological maturity & 49 \\
& FL-LF & Photothermal time between first flower and the end of leaf expansion & 65 \\
& LFMAX & Maximum leaf photosynthesis rate $\left(\mathrm{mg} \mathrm{CO}_{2} \mathrm{~m}^{-2} \mathrm{~s}^{-1}\right)$ & \\
& SLAVR & Specific leaf area in standard growth conditions $\left(\mathrm{cm}^{2} \mathrm{~g}^{-1}\right)$ & 1.49 \\
& XFRT & Maximum fraction of daily growth that is partitioned to bolls & 141 \\
& THRSH & Maximum ratio of seed cotton weight and boll weight (threshing percentage) & 0.71 \\
\hline Ecotype parameters & PL-EM & Thermal time between planting and emergence & 40 \\
(COGRO046.ECO) & FL-VS & Photothermal time from first flower to the last leaf on the main stem & 25 \\
& RWDTH & Relative width of the ecotype & 1.1 \\
& RHGHT & Relative height of the ecotype & 0.74 \\
\hline Species parameters & KMIN & Minimum basal crop coefficient & 0.0 \\
(COGRO046.SPE) & KMAX & Maximum basal crop coefficient & 1.1 \\
& SKC & Shaping coefficient for basal crop coefficient from simulated LAI & 0.65 \\
\hline
\end{tabular}


RMSE metric, the best parameter combination was chosen by minimizing the rank sum over the RMSE metrics for all field measurement types. This Sobol sampling approach to model parameterization was somewhat unorthodox but represented an effort to automate model parameterization activities by thoroughly evaluating a parameter space using multiple types of data collected under diverse conditions. The resulting parameterization (tables 1 and 2) was used for both growing seasons for all subsequent simulation analyses, including efforts to (1) recalculate the 2014 and 2015 irrigation schedules post-hoc and (2) demonstrate the responsiveness of model-simulated $K_{c b}$ to variation in planting density, N fertilization rate, EM-FL parameter effects on anthesis date, and growing degree day differences over a 30 -year AZMET weather history at MAC.

\section{RESULTS AND DISCUSSION}

\section{APPLIED IRRIGATION}

With post-hoc corrections from irrigation machine calibration efforts, the total irrigation applied to the FAO, CMD, and WST treatments was respectively 757, 763, and $561 \mathrm{~mm}$ in 2014 and 939, 937, and $711 \mathrm{~mm}$ in 2015 (fig. 2 and table 3). Thus, seasonal irrigation recommendations from the FAO-56 spreadsheet and the CSM-CROPGRO-Cotton model were similar. However, the timing for the FAO and CMD irrigation schedules was not the same. After intentional identical watering of both FAO and CMD treatments in April and May, the CMD treatment immediately lagged in applied irrigation when the scheduling tools were first used in June of both seasons (table 3). In June of 2014 and 2015, CMD lagged FAO by 20 and $10 \mathrm{~mm}$, respectively. However, the CMD treatment caught up to FAO in July, with 20 and $12 \mathrm{~mm}$ more irrigation applied in 2014 and 2015, respectively. Therefore, as compared to the FAO-56 spreadsheet, CSM-CROPGRO-Cotton recommended less water during the squaring stage and more water during the flowering stage. In August, the FAO and CMD treatments received similar irrigation amounts. At the end of the irrigation season in September, the CMD treatment received an additional irrigation in 2014, while the FAO treatment received an additional irrigation in 2015. These results demonstrate the reasonable capability of the CSM-CROPGRO-Cotton model

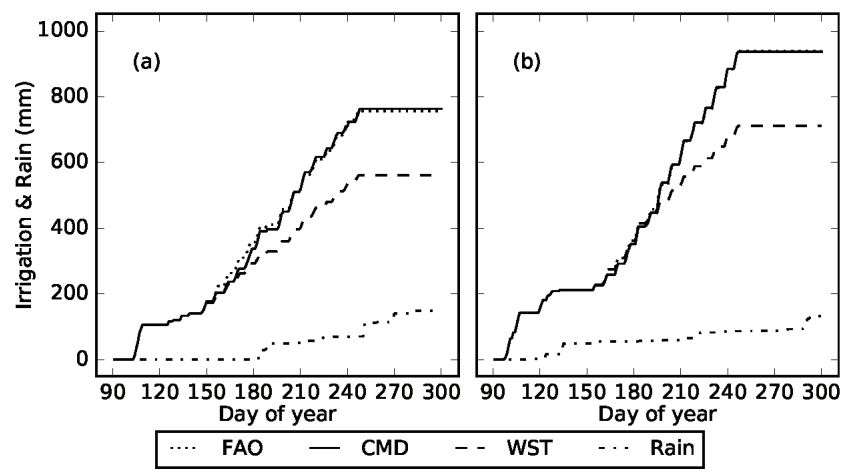

Figure 2. Cumulative rainfall and applied irrigation for the FAO-56 spreadsheet treatment (FAO), CSM-CROPGRO-Cotton crop model treatment (CMD), and water-stressed treatment (WST) from April through October at Maricopa, Arizona in (a) 2014 and (b) 2015.
Table 3. Rainfall, grass reference evapotranspiration $\left(\mathrm{ET}_{o}\right)$, and applied irrigation for the FAO-56 spreadsheet treatment (FAO), CSMCROPGRO-Cotton crop model treatment (CMD), and water-stressed treatment (WST) in 2014 and 2015 at Maricopa, Arizona.

\begin{tabular}{lcccccc} 
& DOY & $\begin{array}{c}\text { Rain } \\
(\mathrm{mm})\end{array}$ & $\begin{array}{c}\text { FAO } \\
(\mathrm{mm})\end{array}$ & $\begin{array}{c}\text { CMD } \\
(\mathrm{mm})\end{array}$ & $\begin{array}{c}\text { WST } \\
(\mathrm{mm})\end{array}$ & $\begin{array}{c}\mathrm{ET}_{o} \\
(\mathrm{~mm})\end{array}$ \\
\hline 2014 & & & & & & \\
Apr. (pre-watering) & $91-120$ & 0 & 107 & 107 & 107 & 190 \\
May (emergence) & $121-151$ & 0 & 70 & 70 & 70 & 243 \\
June (squaring) & $152-181$ & 0 & 180 & 160 & 120 & 261 \\
July (flowering) & $182-212$ & 54 & 200 & 220 & 134 & 245 \\
Aug. (boll fill) & $213-243$ & 17 & 173 & 166 & 116 & 206 \\
Sept. (maturity) & $244-273$ & 70 & 27 & 40 & 18 & 165 \\
\hline Total & $91-273$ & 140 & 757 & 763 & 561 & 1310 \\
\hline 2015 & & & & & & \\
Apr. (pre-watering) & $91-120$ & 3 & 155 & 155 & 155 & 190 \\
May (emergence) & $121-151$ & 46 & 57 & 57 & 57 & 211 \\
June (squaring) & $152-181$ & 7 & 150 & 140 & 150 & 244 \\
July (flowering) & $182-212$ & 10 & 302 & 314 & 195 & 244 \\
Aug. (boll fill) & $213-243$ & 20 & 219 & 219 & 123 & 231 \\
Sept. (maturity) & $244-273$ & 1 & 56 & 52 & 31 & 169 \\
\hline Total & $91-273$ & 87 & 939 & 937 & 711 & 1290 \\
\hline
\end{tabular}

with updated FAO-56 ET routines to recommend similar irrigation schedules as compared to an FAO-56 spreadsheet that was previously well-tested for cotton irrigation scheduling in central Arizona. Successful use of CSM-CROPGROCotton for irrigation scheduling during two cotton growing seasons increased confidence in the ability of the model to guide in-season management decisions.

\section{ANalysis of Field Data}

Results of hierarchical linear mixed modeling and multiple comparisons tests demonstrated the differences in crop growth and yield among the irrigation management treatments (table 4). In 2014, LAI and canopy weight were not different for the FAO and CMD treatments on any of the measurement dates. However, LAI and canopy weight for the WST treatment were lower $(\mathrm{p}<0.05)$ than for the FAO and CMD treatments in July (DOY 203) and August (DOY 230). Fiber yield, cottonseed yield, seed cotton yield, and yield monitor measurements were significantly different among all three irrigation management treatments in $2014(p<0.05)$. Subtle differences in irrigation management, particularly a $20 \mathrm{~mm}$ reduction in June irrigation followed by a $20 \mathrm{~mm}$ increase in July irrigation (table 3), led to higher cotton yield for CMD as compared to FAO (table 4), which was measured in two independent yield data sets (i.e., from bagged yield samples and from a cotton yield monitor). In 2015 , LAI was different $(p<0.05)$ among all three irrigation management treatments late in the season (DOYs 229 and 243), although FAO had the highest LAI on DOY 229 while CMD had the highest LAI on DOY 243. Canopy weight was lower $(\mathrm{p}<0.05)$ for WST as compared to both FAO and CMD on two dates in August (DOY 215 and 243), although there were no canopy weight differences in mid-August (DOY 229). Such inconsistencies in LAI and canopy weight results can be explained by higher measurement uncertainty for these canopy traits and only two replications. Fiber yield was different $(\mathrm{p}<0.05)$ among all three irrigation treatments in 2015, with the CMD treatment again yielding the highest. Cottonseed yield, seed cotton yield, and yield monitor measurements in 2015 were not different between the FAO and CMD treat- 
Table 4. Hierarchical linear mixed modeling and multiple comparisons tests for leaf area index (LAI, $\mathrm{m} \mathrm{m}^{-1}$ ) and canopy weight (CWT, $\mathrm{kg} \mathrm{ha}^{-1}$ ) on different days of the year (DOY) and fiber yield (FBR, $\mathrm{kg} \mathrm{ha}^{-1}$ ), cottonseed yield (SED, kg ha-1), seed cotton yield (SDC, kg ha ${ }^{-1}$ ), and cotton yield monitor measurements (YDM, kg ha-1) for the FAO-56 spreadsheet treatment (FAO), CSM-CROPGRO-Cotton crop model treatment (CMD), and water-stressed treatment (WST) in 2014 and 2015 at Maricopa, Arizona. Means in the same row followed by different letters are significantly different $(p<0.05)$.

\begin{tabular}{|c|c|c|c|c|c|}
\hline Year & & DOY & FAO & CMD & $\overline{\text { WST }}$ \\
\hline \multirow[t]{10}{*}{2014} & LAI & 175 & $0.94 \mathrm{a}$ & $0.96 \mathrm{a}$ & $0.72 \mathrm{a}$ \\
\hline & & 203 & $4.51 \mathrm{a}$ & $4.93 \mathrm{a}$ & $2.19 \mathrm{~b}$ \\
\hline & & 230 & $5.11 \mathrm{a}$ & $5.18 \mathrm{a}$ & $3.21 \mathrm{~b}$ \\
\hline & CWT & 175 & $1330 \mathrm{a}$ & $1286 \mathrm{a}$ & $1254 \mathrm{a}$ \\
\hline & & 203 & $8263 \mathrm{a}$ & $7406 \mathrm{a}$ & $4924 \mathrm{~b}$ \\
\hline & & 230 & $13390 \mathrm{a}$ & $13204 \mathrm{a}$ & $8991 \mathrm{~b}$ \\
\hline & FBR & 316 & $1573 \mathrm{a}$ & $1952 \mathrm{~b}$ & $924 \mathrm{c}$ \\
\hline & SED & 316 & $2419 \mathrm{a}$ & $3023 \mathrm{~b}$ & $1473 \mathrm{c}$ \\
\hline & SDC & 316 & $3992 \mathrm{a}$ & $4975 \mathrm{~b}$ & $2397 \mathrm{c}$ \\
\hline & YDM & 323 & $1513 \mathrm{a}$ & $1771 \mathrm{~b}$ & $1032 \mathrm{c}$ \\
\hline \multirow[t]{18}{*}{2015} & LAI & 161 & $0.22 \mathrm{a}$ & $0.23 \mathrm{a}$ & $0.17 \mathrm{~b}$ \\
\hline & & 174 & $0.96 \mathrm{a}$ & $1.06 \mathrm{a}$ & $1.04 \mathrm{a}$ \\
\hline & & 188 & $2.40 \mathrm{a}$ & $2.51 \mathrm{a}$ & $2.90 \mathrm{a}$ \\
\hline & & 203 & $3.12 \mathrm{a}$ & $4.22 \mathrm{~b}$ & $2.90 \mathrm{a}$ \\
\hline & & 215 & $3.47 \mathrm{a}$ & $4.00 \mathrm{a}$ & $3.34 \mathrm{a}$ \\
\hline & & 229 & $5.93 \mathrm{a}$ & $5.22 \mathrm{~b}$ & $4.14 \mathrm{c}$ \\
\hline & & 243 & $4.69 \mathrm{a}$ & $5.69 \mathrm{~b}$ & $4.28 \mathrm{c}$ \\
\hline & CWT & 161 & $197 a$ & $213 a$ & $152 \mathrm{~b}$ \\
\hline & & 174 & $1325 \mathrm{a}$ & $1225 \mathrm{a}$ & $1160 \mathrm{a}$ \\
\hline & & 188 & $3049 \mathrm{a}$ & $3037 \mathrm{a}$ & $3360 \mathrm{a}$ \\
\hline & & 203 & $5087 \mathrm{a}$ & $6514 \mathrm{~b}$ & $4935 \mathrm{a}$ \\
\hline & & 215 & $7343 \mathrm{a}$ & $7469 \mathrm{a}$ & $6873 \mathrm{~b}$ \\
\hline & & 229 & $10839 \mathrm{a}$ & $10817 \mathrm{a}$ & $9192 \mathrm{a}$ \\
\hline & & 243 & $14674 \mathrm{a}$ & $13911 \mathrm{a}$ & $11970 \mathrm{~b}$ \\
\hline & FBR & 321 & $2135 \mathrm{a}$ & $2327 \mathrm{~b}$ & $1141 \mathrm{c}$ \\
\hline & SED & 321 & $3238 \mathrm{a}$ & $3467 \mathrm{a}$ & $1742 \mathrm{~b}$ \\
\hline & SDC & 321 & $5373 \mathrm{a}$ & $5795 \mathrm{a}$ & $2883 \mathrm{~b}$ \\
\hline & YDM & 327 & $1920 \mathrm{a}$ & $2007 \mathrm{a}$ & $1107 \mathrm{~b}$ \\
\hline
\end{tabular}

ments, but these measurements were lower for the WST treatment $(\mathrm{p}<0.05)$. In both the 2014 and 2015 cotton growing seasons, the irrigation schedule recommended by CSMCROPGRO-Cotton, which favored reduced irrigation in June and increased irrigation during anthesis in July, provided significantly higher fiber yield than the schedule recommended by the FAO-56 spreadsheet. Dynamic simulation of the $K_{c b}$ curve via simulated LAI and greater detail in the simulated soil moisture profile may have guided the crop growth model to these improved management recommendations.

\section{EVAPOTRANSPIRATION}

After post-hoc updating and reparameterization, the FAO-56 spreadsheet and the CSM-CROPGRO-Cotton model were able to simulate cumulative ET from squaring (early June) to maturity (late September) with RMSEs less than 13\% (fig. 3). With one exception, simulations of 2014 ET were better than 2015 ET. In 2014, the FAO-56 spreadsheet simulated ET for the FAO treatment with an RMSE of $2.9 \%$, while CSM-CROPGRO-Cotton simulated ET for the CMD treatment with an RMSE of 7.1\% (figs. $3 a$ and $3 b$ ). With RMSEs less than $6 \%$, simulations of ET for both the spreadsheet and the crop model responded appropriately to water deficit conditions in the WST treatment. For reasons that are unclear, both the FAO-56 spreadsheet and CSMCROPGRO-Cotton tended to overestimate ET in 2015, particularly in the late season from mid-August through September. In 2015, the FAO-56 spreadsheet simulated ET for
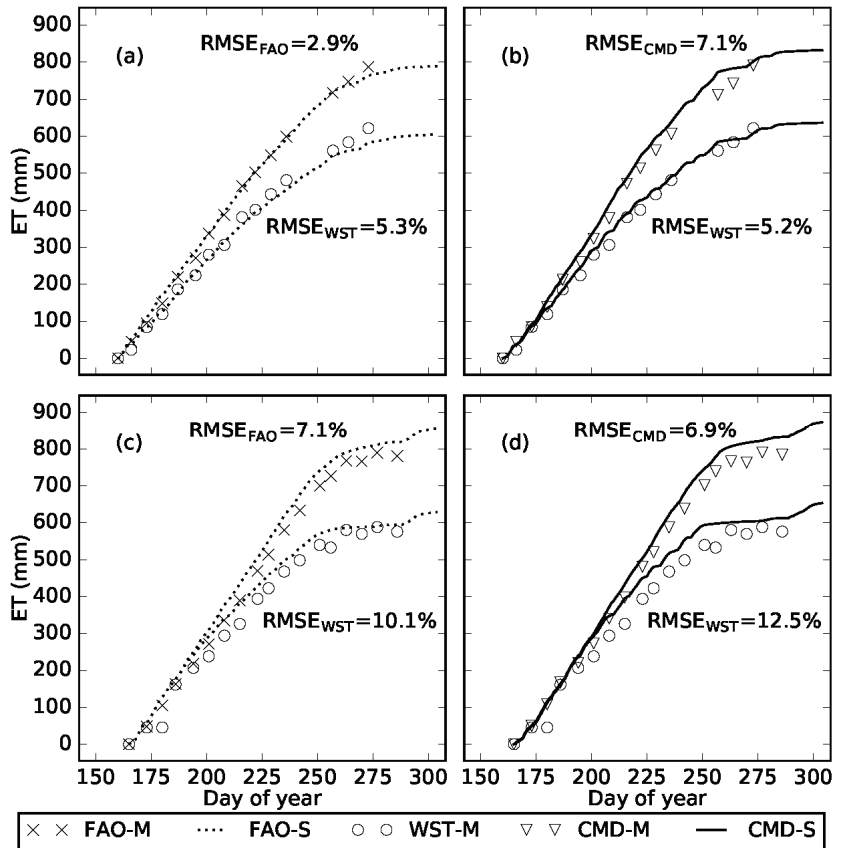

Figure 3. Cumulative measured evapotranspiration (ET) from the FAO-56 spreadsheet treatment (FAO-M), CSM-CROPGRO-Cotton crop model treatment (CMD-M), and water-stressed treatment (WSTM) with cumulative ET calculated post-hoc by the (a) FAO-56 spreadsheet (FAO-S) and (b) CSM-CROPGRO-Cotton model (CMD-S) in 2014 and by the (c) FAO-56 spreadsheet and (d) CSM-CROPGROCotton model in 2015 at Maricopa, Arizona. Based on the availability of neutron moisture meter readings, cumulative ET was calculated from day of year (DOY) 160 through DOY 273 in 2014 and from DOY 165 through DOY 286 in 2015.

the FAO treatment with an RMSE of $7.1 \%$, while CSMCROPGRO-Cotton simulated ET for the CMD treatment with an RMSE of $6.9 \%$ (figs. 3c and 3d). Similar to 2014, both irrigation scheduling tools responded appropriately to water deficit conditions in the 2015 WST treatment. However, the WST RMSEs were $10.1 \%$ and $12.5 \%$ for the FAO56 spreadsheet and CSM-CROPGRO-Cotton, respectively, which were the highest among the post-hoc ET simulations. Overall, both irrigation scheduling tools were able to appropriately simulate cotton ET under both well-watered and water-limited conditions.

\section{CROP COEFFICIENT}

The crop coefficient $\left(K_{c}\right)$ concept is central to ET estimation and irrigation scheduling techniques based on FAO-56 (Allen et al., 1998; Jensen et al., 2016). Because $K_{c}$ normalizes crop ET relative to reference ET (eq. 2), it removes the fluctuations in daily ET data due to variability in atmospheric demand while still providing a conceptual understanding of temporal ET dynamics. Thus, $K_{c}$ is a better metric than ET itself for visual comparison of daily water use calculations between the FAO-56 spreadsheet and CSMCROPGRO-Cotton. Prior to full crop cover from planting to anthesis (approximately DOY 121 through DOY 185), the spikes in the calculated $K_{c}$ were caused by increased simulated soil water evaporation after wetting events from irrigation and rainfall (figs. 4 and 5). From anthesis through boll filling (approximately DOY 185 through DOY 247), $K_{c}$ remained higher than 1.0 when the cotton was well-watered 

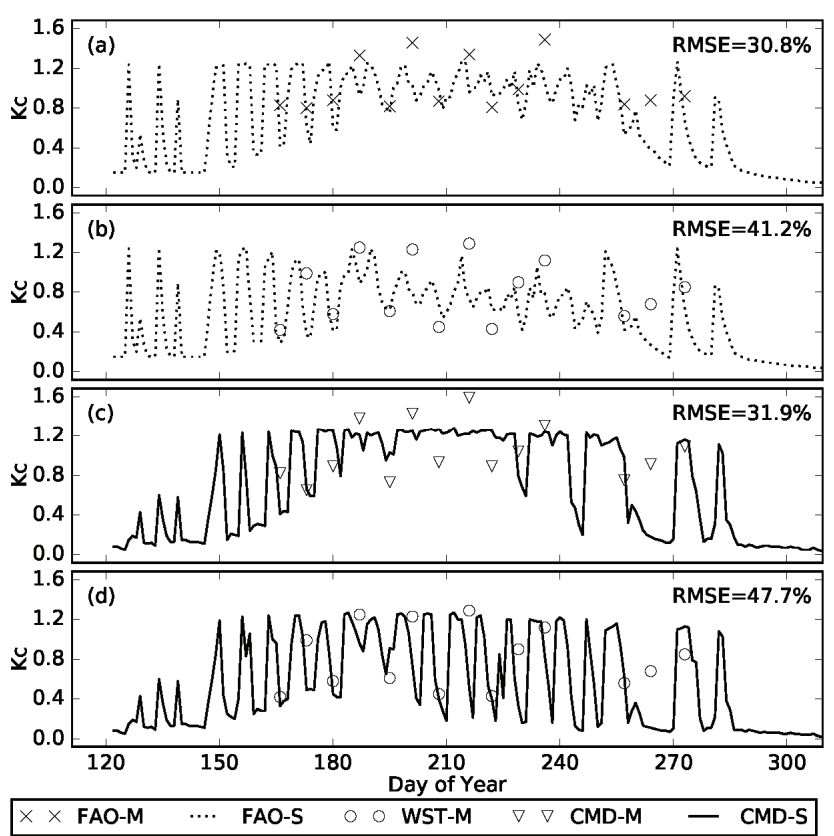

Figure 4. Post-hoc simulated crop coefficient $\left(K_{c}=\mathbf{E T} / \mathbf{E T}\right.$ ) for the FAO-56 spreadsheet (FAO-S) with measured data from the (a) FAO56 spreadsheet (FAO-M) and (b) water-stressed (WST-M) treatments and for the CSM-CROPGRO-Cotton model (CMD-S) with measured data from the (c) crop growth model (CMD-M) and (d) water-stressed (WST-M) treatments in 2014 at Maricopa, Arizona.
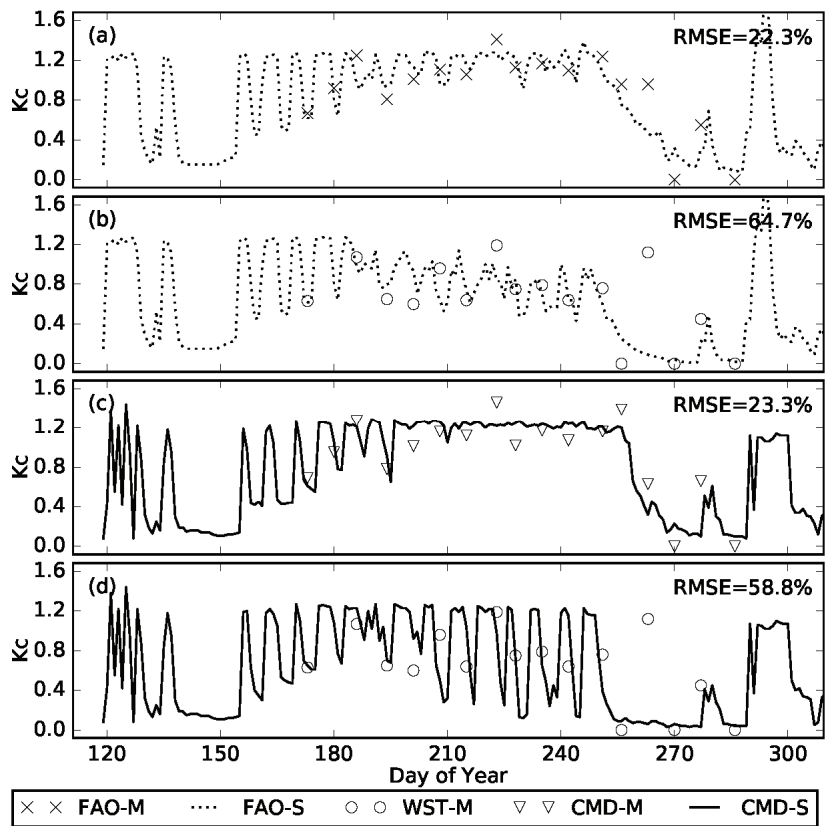

Figure 5. Post-hoc simulated crop coefficient $\left.\left(K_{c}=\mathbf{E T} / \mathbf{E T}\right)_{o}\right)$ for the FAO-56 spreadsheet (FAO-S) with measured data from the (a) FAO56 spreadsheet (FAO-M) and (b) water-stressed (WST-M) treatments and for the CSM-CROPGRO-Cotton model (CMD-S) with measured data from the (c) crop growth model (CMD-M) and (d) water-stressed (WST-M) treatments in 2015 at Maricopa, Arizona.

and readily transpiring. Lower $K_{c}$ in this period resulted from water-stressed conditions. Thus, the $K_{c}$ data provided insights into how the different scheduling techniques calculated reductions in mid-season transpiration due to water deficit. After irrigation termination in the late season (DOY
247 onward), spikes in $K_{c}$ were again attributed to wetting events from rainfall as the crop senesced.

Generally, post-hoc $K_{c}$ calculations with the FAO-56 spreadsheet and CSM-CROPGRO-Cotton were in agreement with the temporal patterns in measured $K_{c}$, although uncertainty in the $K_{c}$ measurements can be attributed to the weekly measurement interval of the neutron moisture meters. In 2014, the FAO-56 spreadsheet calculated $K_{c}$ for the FAO and WST treatments with RMSEs of $30.8 \%$ and $41.2 \%$, respectively (figs. $4 \mathrm{a}$ and 4b). CSM-CROPGRO-Cotton simulated $K_{c}$ for the 2014 CMD and WST treatments with RMSEs of $31.9 \%$ and $47.7 \%$, respectively (figs. $4 c$ and $4 d$ ). In 2015, the FAO-56 spreadsheet calculated $K_{c}$ for the FAO and WST treatments with RMSEs of $22.3 \%$ and $64.7 \%$, respectively (figs. 5a and 5b), while CSM-CROPGRO-Cotton simulated $K_{c}$ for the CMD and WST treatments with RMSEs of $23.3 \%$ and $58.8 \%$, respectively (figs. $5 \mathrm{c}$ and $5 \mathrm{~d}$ ). For wellwatered cotton treatments, the FAO-56 spreadsheet and CSM-CROPGRO-Cotton simulated $K_{c}$ with similar RMSEs, although the RMSEs for the former method were better than the latter by about $1 \%$ in both seasons. Temporal $K_{c}$ patterns were also visually different in the mid-season under wellwatered conditions, particularly in 2015 . Whereas $K_{c}$ for the FAO-56 spreadsheet tended to fluctuate between 0.9 and 1.3 at mid-season (fig. $5 \mathrm{a}$ ), the $K_{c}$ for CSM-CROPGRO-Cotton tended toward a value of 1.2 with little variability (fig. $5 \mathrm{c}$ ). These differences were likely related to different methodologies for simulating the soil profile water balance, water uptake within the crop root zone, and stress coefficients, which ultimately led to reduced transpiration in the models. With water-stressed conditions in both seasons, the RMSEs between measured and simulated $K_{c}$ were often more than twice as high as that for the well-watered FAO and CMD treatments. Thus, both models had greater difficulty in simulating $K_{c}$ with water stress. Additionally, at mid-season with water stress, CSM-CROPGRO-Cotton had much wider fluctuations in $K_{c}$, which varied between 0.2 and 1.2 (figs. $4 \mathrm{~d}$ and 5d). On the other hand, the FAO-56 spreadsheet calculated mid-season $K_{c}$ between 0.6 and 1.0 under these conditions (fig. $4 \mathrm{~b}$ and $5 \mathrm{~b}$ ). These differences illustrate why $K_{c}$ plots are valuable for comparison of different crop ET calculation methods. While both the FAO-56 spreadsheet and CSM-CROPGRO-Cotton simulated cumulative ET very well and very similarly (fig. 3 ), the $K_{c}$ plots revealed subtle differences in the calculation of daily ET between the two approaches. Because the ET measurement approach in this study did not permit ET assessments on a daily basis, further model evaluations are warranted using ET data with more appropriate temporal resolution, such as that provided by weighing lysimetry (Evett et al., 2016). Such evaluations could focus on identifying modeling methodologies that better simulate patterns in daily ET, which could lead to possible solutions for further model refinement and improvement.

\section{Root Zone SoIL Moisture Depletion}

Similar to $K_{c}$, root zone soil moisture depletion is another concept that is central to FAO-56, and it is a primary output of the FAO-56 water balance model. On the other hand, CSM-CROPGRO-Cotton does not calculate depletion directly, and it must be calculated from simulated outputs for 
soil moisture and rooting depth in addition to inputs for drained upper limit and lower limit (table 1). Generally, depletion calculations by the FAO-56 spreadsheet were sensitive to inputs for available soil water holding capacity, irrigation, and rooting depth. Calculations of measured depletion and crop model-simulated depletion were sensitive to soil moisture data and assumptions for drained upper limit, lower limit, and rooting depth. Because of these sensitivities, measured and modeled depletion results were highly dependent on estimates of the metrics required for its calculation.

Because of issues with the irrigation system calibration, cotton was irrigated less in 2014 than 2015 (fig. 2), leading to reduced cotton yield in 2014 as compared to 2015 (table 4). Nevertheless, measured depletion did not exceed $45 \%$ for the FAO and CMD treatments in 2014 (figs. 6a and 6c) until irrigation was terminated in the late season. For the WST treatment, measured depletion exceeded $45 \%$ after 20 July 2014 (DOY 201; figs. 6b and 6d). In 2015, measured depletion exceeded $45 \%$ for the FAO treatment on all measurement dates in July (DOYs 180 through 208; fig. 7a). Given that the FAO yields were higher in 2015 than in 2014 (table 4), it is unexpected that the FAO depletion levels in 2015 were generally higher than in 2014 (figs. 6a and 7a). Possibly, there was an unresolved issue with the FAO neutron moisture measurements. For the CMD treatment, 45\% depletion was exceeded only on 13 July 2015 (DOY 194; fig. 7c). After switching to higher flow-rate nozzles in midJuly 2015, measured depletion values were below $45 \%$ for FAO and CMD treatments until irrigation was terminated in the late season (figs. 7a and 7c). In addition, unlike the FAO treatment, mid-season depletion levels for the CMD treatment were lower in 2015 as compared to 2014, as would be

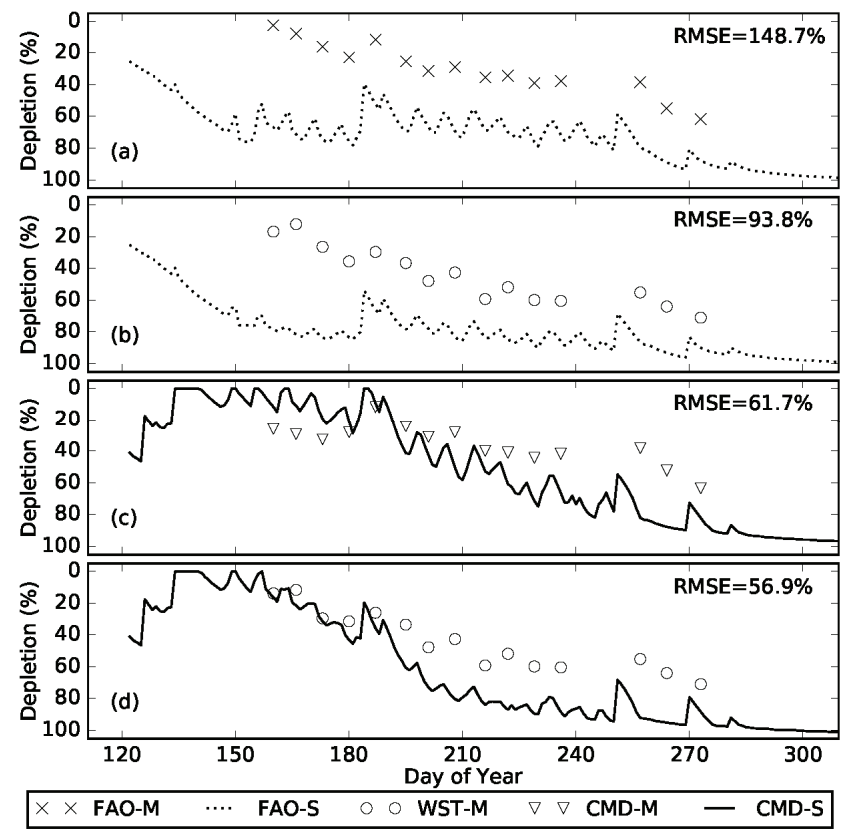

Figure 6. Post-hoc simulated root zone soil moisture depletion for the FAO-56 spreadsheet (FAO-S) with measured data from the (a) FAO56 spreadsheet (FAO-M) and (b) water-stressed (WST-M) treatments and for the CSM-CROPGRO-Cotton model (CMD-S) with measured data from the (c) crop growth model (CMD-M) and (d) water-stressed (WST-M) treatments in 2014 at Maricopa, Arizona.
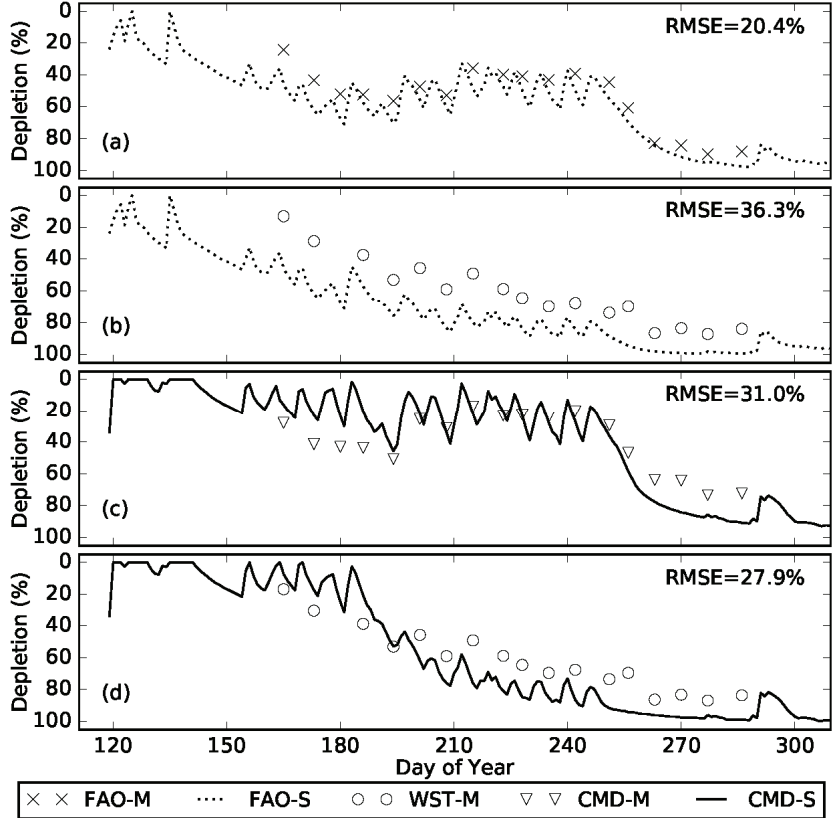

Figure 7. Post-hoc simulated root zone soil moisture depletion for the FAO-56 spreadsheet (FAO-S) with measured data from the (a) FAO56 spreadsheet (FAO-M) and (b) water-stressed (WST-M) treatments and for the CSM-CROPGRO-Cotton model (CMD-S) with measured data from the (c) crop growth model (CMD-M) and (d) water-stressed (WST-M) treatments in 2015 at Maricopa, Arizona.

expected given the higher yield in 2015 (table 4). For the WST treatment, measured depletion exceeded $45 \%$ beginning on 13 July 2015 (DOY 194) and continued through the remainder of the growing season (figs. $7 \mathrm{~b}$ and $7 \mathrm{~d}$ ).

Post-hoc depletion calculations with both the FAO-56 spreadsheet and CSM-CROPGRO-Cotton were generally higher than measured depletion, although depletion simulated by the crop model generally matched measurements better than the FAO-56 spreadsheet. CSM-CROPGRO-Cotton simulated depletion for the $2014 \mathrm{CMD}$ and WST treatments with RMSEs of $61.7 \%$ and $56.9 \%$, respectively (figs. 6c and 6d), while depletion RMSEs for the FAO-56 spreadsheet exceeded $90 \%$. This result is unexpected, especially considering that the initial depletion was lower for the FAO-56 spreadsheet as compared to CSM-CROPGRO-Cotton (fig. 6). Nonetheless, in the four weeks following planting in 2014, ET calculated by the FAO-56 spreadsheet $(85 \mathrm{~mm})$ was $34 \mathrm{~mm}$ higher than that simulated by CSMCROPGRO-Cotton $(51 \mathrm{~mm})$. In addition, relatively light irrigation was used to emerge the crop in 2014, so little water input was available to offset the water losses calculated by the FAO-56 spreadsheet during the early season. The result was increasing depletion calculated by the FAO-56 spreadsheet in the weeks following planting, and simulated depletion exceeded 45\% on 15 May 2014 (DOY 135). According to the FAO-56 spreadsheet, depletion never recovered to a value below $45 \%$ with the water inputs provided during the remainder of the 2014 season (fig. 6a). In addition to simulating lower ET amounts after planting, the CSM-CROPGRO-Cotton model simulated a layered soil profile and permitted the water content in each simulated layer to exceed the drained upper limit. Thus, the model was better able to 
simulate additional water supplies within the root zone, to redistribute water within the soil profile, and to permit root growth into layers with more favorable water contents. This resulted in a buffering effect on simulated depletion in the 2014 early season with CSM-CROPGRO-Cotton. Simulated depletion trended to lower values during this period (figs. $6 \mathrm{c}$ and $6 \mathrm{~d}$ ) and remained low until transpiration demand increased later in the season, a pattern that matched depletion measurements from neutron moisture meters. With CSMCROPGRO-Cotton, $45 \%$ depletion was not exceeded until 21 July 2014 (DOY 202), with water deficits leading to further increases thereafter (fig. 6c).

In 2015, post-hoc depletion calculations with both the FAO-56 spreadsheet and CSM-CROPGRO-Cotton were much better than in 2014 (fig. 7). Water inputs in the early season were much higher in 2015 than in 2014 (fig. 2), which resulted in relatively low initial depletion for both tools in 2015. The FAO-56 spreadsheet calculated depletion for the 2015 FAO and WST treatments with RMSEs of $20.4 \%$ and $36.3 \%$, respectively (figs. $7 \mathrm{a}$ and $7 \mathrm{~b}$ ). CSM-CROPGROCotton simulated depletion for the CMD and WST treatments with RMSEs of $31.0 \%$ and $27.9 \%$, respectively (figs. 7c and 7d). Similar to 2014, the FAO-56 spreadsheet calculated a generally increasing trend in depletion in the 2015 early season due to water deficits from underirrigation (fig. 7a), and calculated depletion exceeded $45 \%$ for the FAO treatment on 2 June 2015 (DOY 153). After switching to larger nozzles in mid-July (DOY 190), calculated depletion recovered and stabilized but still exceeded $45 \%$ on dry days between irrigation events. This result matched the measured depletion much more closely than the previous season and was the best effort to calculate depletion by either tool in either season. For CSM-CROPGRO-Cotton simulating the CMD treatment, $45 \%$ depletion was not exceeded in 2015 until irrigation was terminated at the end of the season (fig. 7c), except for one day in mid-July (DOY 194). Crop model simulations of the WST treatment in 2015 were excellent, with the lowest RMSE (27.9\%) among all efforts to calculate depletion with water stress (fig. 7d). Efforts to fit the crop model's soil moisture simulation to the neutron moisture measurements using the Sobol sampling scheme (table 2) likely assisted its depletion calculations.

\section{CROP GROWTH}

An important advantage of CSM-CROPGRO-Cotton was its ability to simulate crop growth processes, which was not possible with the FAO-56 spreadsheet. Post-hoc simulations with the crop growth model demonstrated its ability to simulate LAI, canopy weight, and canopy height, with RMSEs less than $21 \%$ in both growing seasons (fig. 8). In 2014, CSM-CROPGRO-Cotton simulated LAI, canopy weight, and canopy height with RMSEs of $13.8 \%, 16.5 \%$, and $16.5 \%$ for the CMD treatment and $20.6 \%, 18.8 \%$, and $10.1 \%$ for the WST treatment, respectively (figs. 8a, 8b, and 8c). In 2015, CSM-CROPGRO-Cotton simulated LAI, canopy weight, and canopy height with RMSEs of $12.5 \%, 8.5 \%$, and $8.4 \%$ for the CMD treatment and $16.4 \%, 19.3 \%$, and $7.7 \%$ for the WST treatment, respectively (figs. 8d, 8e, and 8f). In both growing seasons, LAI and canopy weight were better simulated for the more well-watered CMD treatment, while canopy height was better simulated for the water-stressed treatment. CSM-CROPGRO-Cotton tended to overestimate fiber yield, cottonseed yield, and seed cotton yield in 2014 (fig. 9a), although RMSEs were less than $12 \%$ for the CMD and WST treatments. In 2015, all yield metrics for both the CMD and WST treatments were simulated with RMSEs less than $11 \%$ (fig. 9b), although yield was generally underestimated. Overall, post-hoc CSM-CROPGRO-Cotton simulations demonstrated reasonable ability to estimate cotton growth and yield within acceptable levels of error.

Because CSM-CROPGRO-Cotton can provide crop growth and yield estimates, alternative techniques for determining irrigation schedules using the crop model are possible. Whereas irrigations were scheduled to maintain simulated depletion below $45 \%$ in the present study, future efforts could incorporate simulated crop growth and yield metrics as part of the irrigation decision. For example, dynamic de-
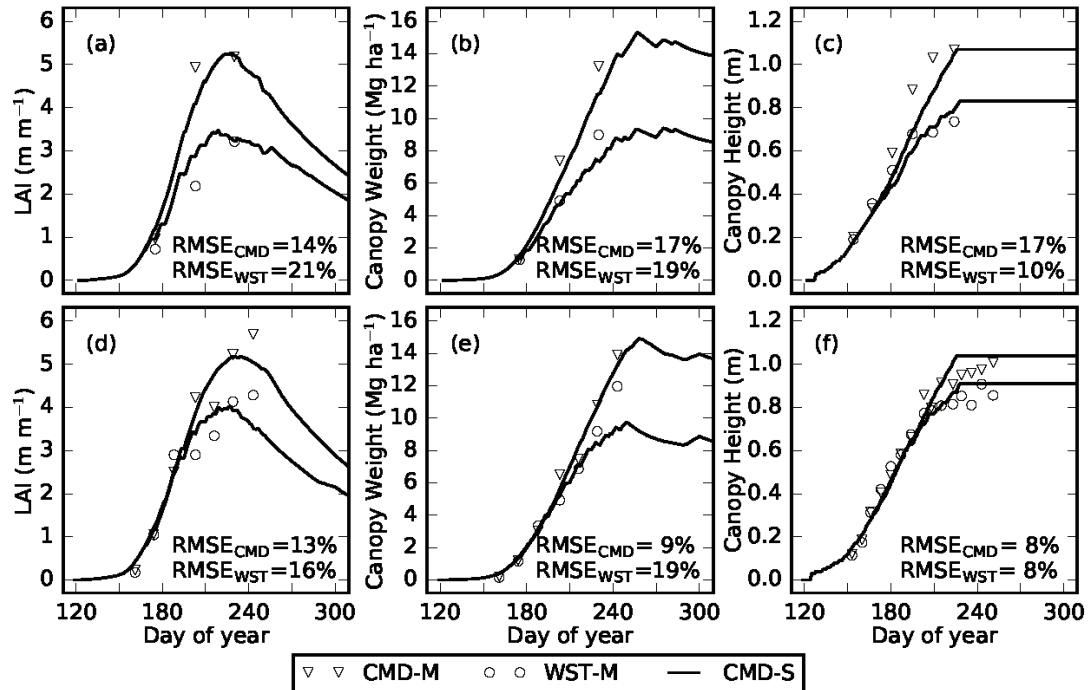

Figure 8. Measured leaf area index (LAI), canopy dry weight, and canopy height for the crop growth model treatment (CMD-M) and waterstressed treatment (WST-M) with post-hoc CSM-CROPGRO-Cotton simulation results (CMD-S) for (a) LAI, (b) canopy dry weight, and (c) canopy height in 2014 and for (d) LAI, (e) canopy dry weight, and (f) canopy height in 2015 at Maricopa, Arizona. 


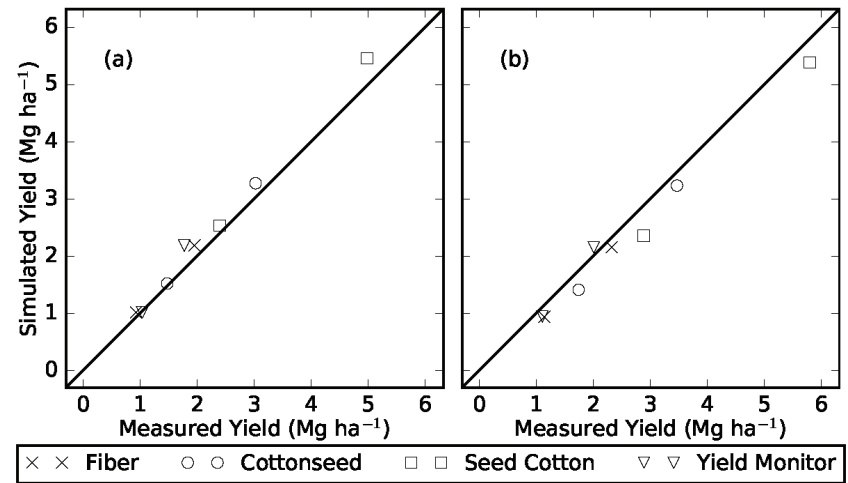

Figure 9. CSM-CROPGRO-Cotton yield simulation results versus measurements for fiber yield, cottonseed yield, and seed cotton yield from bagged samples and versus yield monitor measurements in (a) 2014 and (b) 2015 at Maricopa, Arizona.

pletion thresholds could be established for different crop development stages based on predictions of end-of-season crop yield or water use efficiency. Alternatively, the crop growth model could be used to predict how alternative irrigation management scenarios lead to marginal increases in canopy weight or boll weight between irrigation events, and irrigation strategies that optimize marginal crop growth, boll growth, or water use efficiency while maintaining appropriate soil moisture levels could then be selected for application. In areas where irrigation capacity is insufficient to meet demand, the model can be used to calculate the optimal distribution of available water resources over the growing season to optimize crop yield. A variety of different methodologies for determining irrigation schedules from crop models can be envisioned, all of which aim toward incorporation of simulated data from the crop growth routines and move beyond soil moisture depletion as the sole criteria for irrigation management decisions. Although it is beyond the scope of this study, future efforts on irrigation management with CSM-CROPGRO-Cotton will further address these possibilities.

\section{RESCHEDULING IRRIGATION}

Post-hoc depletion simulations for the FAO and CMD treatments exceeded the $45 \%$ limit (figs. 6 and 7) because of issues with irrigation system calibration and because no data were available for model calibration at this exact field site prior to field experimentation. As a result, the irrigation schedules calculated and administered for in-season field management were suboptimal. Post-hoc recalculation of the irrigation schedules using updated models with data gleaned from the field studies demonstrated depletion calculations that would be expected when maintaining depletion below $45 \%$ (fig. 10). As compared to previous depletion calculations (figs. 6a and 7a), the result showed the sensitivity of the FAO-56 spreadsheet to irrigation inputs, which easily maintained depletion below $45 \%$ with an improved irrigation schedule in both growing seasons (figs. 10a and 10c). One exception was a period of higher depletion in early 2014 (fig. 10a), because the irrigation scheduling tools were not implemented until 28 May 2014 (DOY 148) and 3 June 2015 (DOY 154) for both the field experiment and for this simulation study.

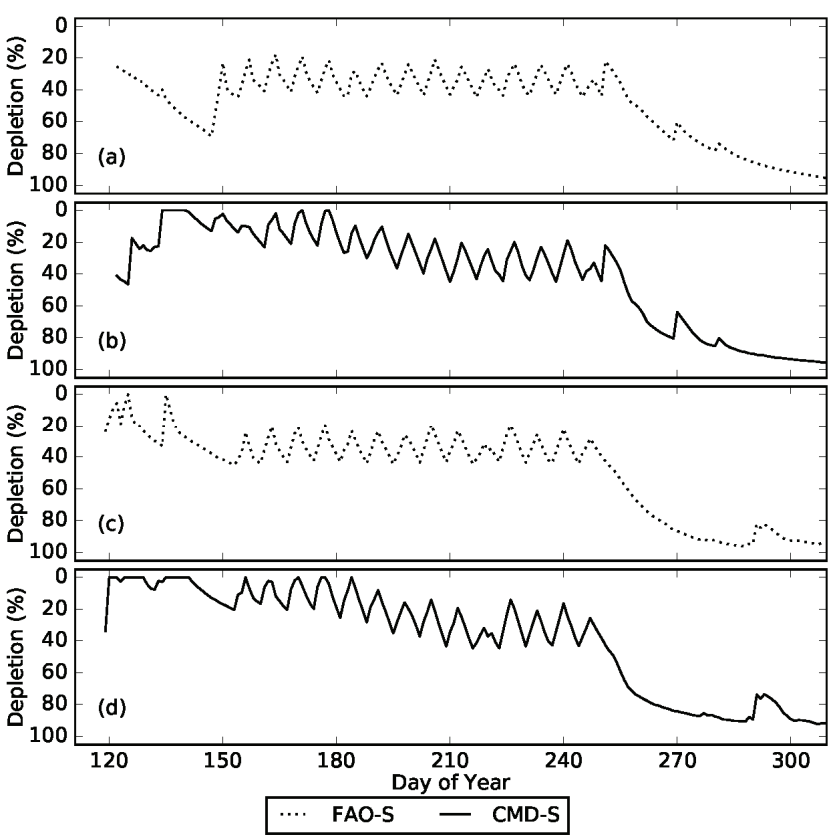

Figure 10. Post-hoc simulated root zone soil moisture depletion after using experimental data to update models and reschedule irrigations using (a) the FAO-56 spreadsheet for 2014, (b) CSM-CROPGRO-Cotton for 2014, (c) the FAO-56 spreadsheet for 2015, and (d) CSMCROPGRO-Cotton for 2015 at Maricopa, Arizona.

The results for calculated depletion (figs. 6, 7, and 10) supported a general observation that the FAO-56 spreadsheet was a more demanding irrigation scheduling tool in the early season, and higher irrigation amounts were often needed to maintain calculated depletion below $45 \%$. On the other hand, CSM-CROPGRO-Cotton was much less demanding in the early season, often calculating that the crop could survive many weeks on stored soil moisture and with less early season irrigation. Occasionally, CSM-CROPGRO-Cotton simulated water stress during this period, even though $45 \%$ depletion was not exceeded. As a result, an additional caveat for irrigation rescheduling with CSM-CROPGRO-Cotton was to ensure that the model's water stress factors were maintained at zero. This assisted scheduling in the early season and led to a gradual decline of minimum weekly depletion levels, reaching $45 \%$ in mid-July (figs. $10 \mathrm{~b}$ and 10d). Further efforts are needed to fully understand these differences in early season irrigation scheduling recommendations between the FAO-56 spreadsheet and CSM-CROPGRO-Cotton, particularly with respect to their impacts on field management, although significantly higher fiber yield was measured in both seasons (table 2) with the CSMCROPGRO-Cotton irrigation schedule. This suggests yield benefits from reduced irrigation in the early season while maintaining full irrigation in the late season. Reducing early season irrigation may promote a healthier and deeper root system, which could improve the crop's ability to meet high water demands during reproductive development later in the season. Current research on primed acclimation in cotton, achieved through smarter irrigation scheduling, supports this theory (Meeks et al., 2016). As compared to the early season, the scheduling tools typically provided similar irrigation rec- 
ommendations in the later season when transpiration demand dominated water use in the field.

The recalculated irrigation recommendations led to seasonal irrigation amounts of 920 and $1000 \mathrm{~mm}$ for the FAO56 spreadsheet and 832 and $948 \mathrm{~mm}$ for CSM-CROPGROCotton in 2014 and 2015, respectively (table 5). As compared to the irrigation schedule applied during the field experiment, the FAO-56 spreadsheet recommended increases of $163 \mathrm{~mm}(+22 \%)$ and $61 \mathrm{~mm}(+6 \%)$ in applied irrigation in 2014 and 2015, respectively. On the other hand, CSMCROPGRO-Cotton recommended increases of $69 \mathrm{~mm}$ $(+9 \%)$ and $11 \mathrm{~mm}(+1 \%)$ in applied irrigation in 2014 and 2015, respectively. Thus, the updated FAO-56 spreadsheet recommended more additional irrigation water than CSMCROPGRO-Cotton to maintain depletion below $45 \%$ in both seasons. In 2015, rescheduling irrigation with CSM-CROPGRO-Cotton led to similar total irrigation amounts (table 5), and depletion patterns were similar for in-season and posthoc irrigation schedules (figs. 7c and 10d). Post-hoc irrigation rescheduling with the FAO-56 spreadsheet led to a $131 \mathrm{~mm}$ increase $(+14 \%)$ and a $1 \mathrm{~mm}$ decrease $(+0 \%)$ in simulated ET in 2014 and 2015, respectively. CSM-CROPGRO-Cotton simulated $58 \mathrm{~mm}$ more $(+6 \%)$ ET in 2014 and $11 \mathrm{~mm}$ more $(+1 \%)$ ET in 2015. Simulated seed cotton yield for CSM-CROPGRO-Cotton increased by $873 \mathrm{~kg} \mathrm{ha}^{-1}$ $(+16 \%)$ in 2014 and by $3 \mathrm{~kg} \mathrm{ha}^{-1}(+0 \%)$ in 2015 . Using CSMCROPGRO-Cotton with the irrigation schedule provided by the FAO-56 spreadsheet, simulated seed cotton yield for FAO increased by $1337 \mathrm{~kg} \mathrm{ha}^{-1}(+26 \%)$ in 2014 and by $404 \mathrm{~kg} \mathrm{ha}^{-1}(+8 \%)$ in 2015 . Thus, to maintain depletion below $45 \%$ with post-hoc rescheduling, the updated FAO-56 spreadsheet recommended the greatest amount of applied irrigation water, which led to the highest simulated seed cotton yield in both growing seasons. These results conflict with measured yield trends for the FAO treatment, which were lower than the CMD treatment in both years (table 4). In particular, measured FAO seed cotton yield in $2014(3992 \mathrm{~kg}$ $\mathrm{ha}^{-1}$, table 4) did not agree with simulations (5119 $\mathrm{kg} \mathrm{ha}^{-1}$, table 5). While the reasons for this are unclear, the simulation results showed similar seed cotton yield values for the irrigation schedules recommended by the tools after updates using field experimental data.

As compared to the in-season FAO irrigation schedule in 2014, post-hoc rescheduling increased irrigation water use efficiency (IWUE $=$ yield/irrigation) by $0.03 \mathrm{~kg} \mathrm{~m}^{-3}(+4 \%)$ and crop water use efficiency (CWUE = yield/ET; $\mathrm{kg} \mathrm{m}^{-3}$ ) by $0.06 \mathrm{~kg} \mathrm{~m}^{-3}(+10 \%)$. In 2015 , the updated FAO irrigation schedule increased IWUE by $0.01 \mathrm{~kg} \mathrm{~m}^{-3}(+1 \%)$ and CWUE by $0.04 \mathrm{~kg} \mathrm{~m}^{-3}(+8 \%)$ (table 5$)$. Compared to the in-season CMD schedule in 2014, rescheduling increased IWUE and CWUE by $0.05 \mathrm{~kg} \mathrm{~m}^{-3}(+6 \%)$ and $0.05 \mathrm{~kg} \mathrm{~m}^{-3}(+9 \%)$, respectively. In 2015, changes to the efficiency metrics were negligible for CMD. Thus, as compared to the irrigation schedules recommended in-season by both the FAO-56 spreadsheet and CSM-CROPGRO-Cotton, adjustments to the parameterization using 2014 and 2015 data assisted both tools in developing updated irrigation schedules that improved or maintained the irrigation efficiency metrics in both seasons. The IWUE and CWUE metrics were higher for CSMCROPGRO-Cotton than for the FAO-56 spreadsheet in 2014 but were similar for both tools in 2015 .

\section{BASAl CROP COEFFICIENT}

The FAO-56 spreadsheet approach effectively calculated crop water use for both well-watered and water-limited conditions (fig. 3). However, it had no capability to respond to other factors that affected the cropping system, because the basal crop coefficients $\left(K_{c b}\right)$ were fixed according to the standard trapezoidal curve specified in FAO-56 (fig. 11). On the other hand, $K_{c b}$ calculations with CSM-CROPGRO-Cotton responded to several factors affecting crop growth and development, because $K_{c b}$ was calculated as a function of simulated LAI. By simulating effects of weather, crop variety, nitrogen fertilizer rate, and plant population with CSMCROPGRO-Cotton, variability in simulated LAI in turn affected simulated $K_{c b}$ and ET. As compared to the FAO-56 spreadsheet, this was a primary advantage of the dual crop coefficient approach in CSM-CROPGRO-Cotton. Previous research has used remote and proximal sensing to estimate in-season $K_{c b}$ for improved ET estimation with the FAO-56 spreadsheet (Hunsaker et al., 2005a, 2005b, 2007a, 2007b). The present study demonstrated that dynamic, in-season $K_{c b}$ curves can also be simulated with a crop growth model.

\section{CONCLUSION}

CSM-CROPGRO-Cotton with an updated ET methodology based on FAO-56 dual crop coefficients (DeJonge and Thorp, 2017) was used for in-season irrigation management during two Arizona cotton seasons. As compared to a well-

Table 5. Simulation results using the post-hoc updated FAO-56 spreadsheet (FAO) and the CSM-CROPGRO-Cotton model (CMD) with the irrigation schedules developed in-season and via post-hoc rescheduling. Calculations of irrigation water use efficiency (IWUE) and crop water use efficiency (CWUE) from the simulation results are provided.

\begin{tabular}{|c|c|c|c|c|c|c|c|c|c|}
\hline & & \multicolumn{4}{|c|}{ FAO } & \multicolumn{4}{|c|}{ CMD } \\
\hline & & In-Season & Reschedule & $\Delta$ & $\% \Delta$ & In-Season & Reschedule & $\Delta$ & $\% \Delta$ \\
\hline \multirow[t]{5}{*}{2014} & Irrigation $(\mathrm{mm})$ & 757 & 920 & +163 & $+22 \%$ & 763 & 832 & +69 & $+9 \%$ \\
\hline & $\mathrm{ET}(\mathrm{mm})$ & 923 & 1054 & +131 & $+14 \%$ & 899 & 957 & +58 & $+6 \%$ \\
\hline & Yield $\left(\mathrm{kg} \mathrm{ha}^{-1}\right)^{[\mathrm{a}]}$ & $5119^{[\mathrm{b}]}$ & $6456^{[\mathrm{b}]}$ & +1337 & $+26 \%$ & 5456 & 6329 & +873 & $+16 \%$ \\
\hline & IWUE $\left(\mathrm{kg} \mathrm{m}^{-3}\right)$ & 0.68 & 0.70 & +0.03 & $+4 \%$ & 0.72 & 0.76 & +0.05 & $+6 \%$ \\
\hline & CWUE $\left(\mathrm{kg} \mathrm{m}^{-3}\right)$ & 0.55 & 0.61 & +0.06 & $+10 \%$ & 0.61 & 0.66 & +0.05 & $+9 \%$ \\
\hline \multirow[t]{5}{*}{2015} & Irrigation $(\mathrm{mm})$ & 939 & 1000 & +61 & $+6 \%$ & 937 & 948 & +11 & $+1 \%$ \\
\hline & $\mathrm{ET}(\mathrm{mm})$ & 1066 & 1065 & -1 & $+0 \%$ & 969 & 980 & +11 & $+1 \%$ \\
\hline & Yield $\left(\mathrm{kg} \mathrm{ha}^{-1}\right)^{[\mathrm{a}]}$ & $5303^{[\mathrm{b}]}$ & $5707^{[\mathrm{b}]}$ & +404 & $+8 \%$ & 5385 & 5388 & +3 & $+0 \%$ \\
\hline & IWUE $\left(\mathrm{kg} \mathrm{m}^{-3}\right)$ & 0.56 & 0.57 & +0.01 & $+1 \%$ & 0.57 & 0.57 & +0.00 & $+0 \%$ \\
\hline & CWUE $\left(\mathrm{kg} \mathrm{m}^{-3}\right)$ & 0.50 & 0.54 & +0.04 & $+8 \%$ & 0.56 & 0.55 & -0.01 & $-1 \%$ \\
\hline
\end{tabular}

[a] Seed cotton yield $=$ fiber + seed.

[b] Simulated by CSM-CROPGRO-Cotton. 

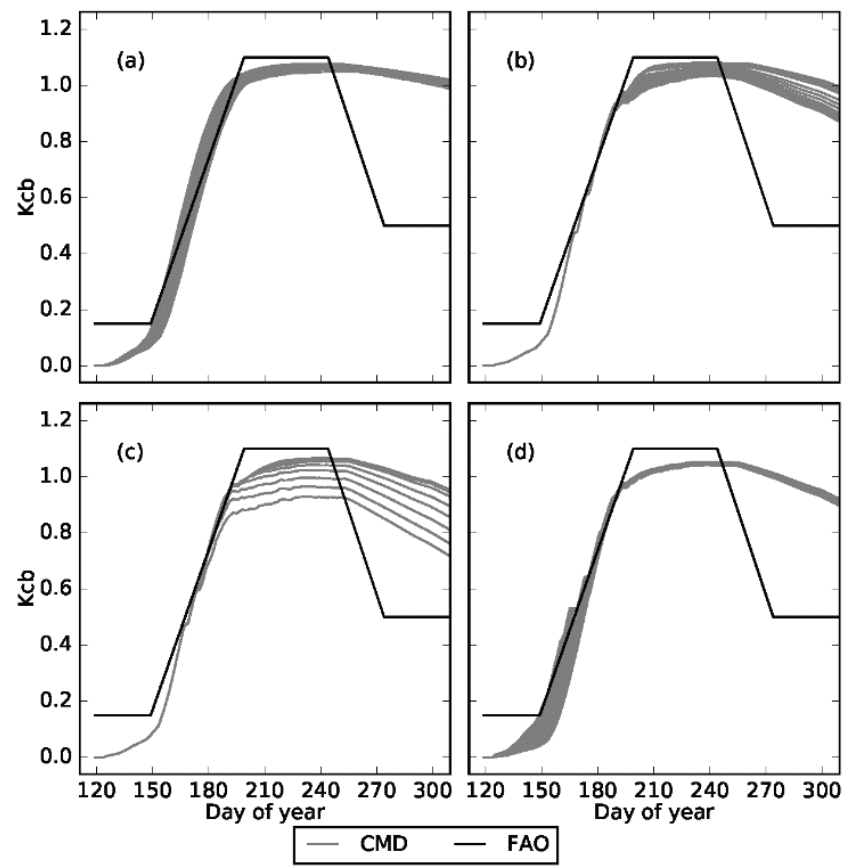

Figure 11. Basal crop coefficients $\left(K_{c b}\right)$ were fixed for the FAO-56 spreadsheet (FAO), but CSM-CROPGRO-Cotton (CMD) simulated $K_{c b}$ responses to (a) weather variability from 1987 to 2016 at Maricopa, Arizona, (b) cultivar parameter variability controlling anthesis date (EM-FL), (c) variable nitrogen application rates from 0 to $360 \mathrm{~kg} \mathrm{ha}^{-1}$, and (d) plant population variability from 5 to 23 plants ha' .

tested FAO-56 spreadsheet tool (Hunsaker et al., 2005a), irrigation management with CSM-CROPGRO-Cotton led to similar irrigation schedules but with slightly different seasonal distributions, equal or higher cotton yield during field experimentation, similar cotton ET calculations, better estimation of root zone soil moisture depletion, and ability to estimate crop growth and yield effects. These results verify the ability of CSM-CROPGRO-Cotton to deliver appropriate in-season irrigation management recommendations that not only follow FAO-56 protocol but also permit decision criteria based on crop growth metrics and water use efficiency and respond to other environmental and management factors apart from a calculated water balance.

Future Arizona cotton field experiments will continue to use CSM-CROPGRO-Cotton to determine in-season irrigation management recommendations, which will permit further refinement of the decision criteria. For example, methodologies that incorporate crop growth metrics, yield predictions, water stress factors, or water use efficiency calculations, in addition to root zone soil moisture depletion, may further optimize irrigation recommendations from the model. In addition, instead of relying on historical weather network data to drive predictions, use of data from local weather forecasts is another way to improve the methodology. Long-term goals include the use of in-season crop growth and soil moisture measurements to assist model simulations and the incorporation of combined measurement and modeling tools within real-time irrigation control systems. Options for delivery of simulation tools to users include web-based programs, smartphone applications, and irrigation system control software. Because the models offer yield prediction capability, the tools could be expanded to focus on applications beyond irrigation management, such as marketing and harvest planning objectives.

Because field data demonstrated increased cotton yield with irrigation schedules that limited early season irrigation, future research should investigate this trend in greater detail. Reduced early season irrigation possibly encourages cotton root growth and increases capacity for water uptake and resilience to water shortage during reproductive development, leading to increased yield. Field studies that test effects of variable irrigation rates and timings will assist assessments of the most appropriate decision criteria for use of crop models as irrigation scheduling tools.

\section{ACKNOWLEDGeMents}

The authors acknowledge USDA-ARS technicians and temporary summer employees for conducting field experiments and collecting field data, including Suzette Maneely, Matthew Hagler, Kendall Stratton (2014), Kylie Stratton (2014), Andrew Kyroudis (2014), Steve Marez (2014), Brooke Conrardy (2015), Riley Anderson (2015), and Cassie Farwell (2015). Cotton Incorporated is also acknowledged for contributing funds to this research.

\section{REFERENCES}

Allen, R. G., Pereira, L. S., Raes, D., \& Smith, M. (1998). Crop evapotranspiration: Guidelines for computing crop water requirements. FAO Irrigation and Drainage Paper No. 56. Rome, Italy: United Nations FAO.

Baumhardt, R. L., Staggenborg, S. A., Gowda, P. H., Colaizzi, P. D., \& Howell, T. A. (2009). Modeling irrigation management strategies to maximize cotton lint yield and water use efficiency. Agron. J., 101(3), 460-468. https://doi.org/10.2134/agronj2008.0041xs

Bausch, W. C., \& Neale, C. M. (1990). Spectral inputs improve corn crop coefficients and irrigation scheduling. Trans. ASAE, 32(6), 1901-1908. https://doi.org/10.13031/2013.31241

Boote, K. J., Jones, J. W., \& Pickering, N. B. (1996). Potential uses and limitations of crop models. Agron. J., 88(5), 704-716. https://doi.org/10.2134/agronj1996.00021962008800050005x

Bronson, K. F., Mon, J., Hunsaker, D. J., Norton, R., \& AndradeSanchez, A. (2015). Improving nitrogen fertilizer management for overhead sprinkler irrigated cotton in the western U.S. Proc. Beltwide Cotton Conf. Cordova, TN: National Cotton Council.

Cammarano, D., Payero, J., Basso, B., Wilkens, P., \& Grace, P. (2012). Agronomic and economic evaluation of irrigation strategies on cotton lint yield in Australia. Crop Pasture Sci., 63(7), 647-655.

DeJonge, K. C., \& Thorp, K. R. (2017). Standardized reference evapotranspiration and dual crop coefficient approach in the DSSAT cropping system model. Trans. ASABE 60(6), 19651981. https://doi.org/10.13031/trans.12321

DeJonge, K. C., Ascough, J. C., Andales, A. A., Hansen, N. C., Garcia, L. A., \& Arabi, M. (2012). Improving evapotranspiration simulations in the CERES-Maize model under limited irrigation. Agric. Water Mgmt., 115, 92-103.

http://dx.doi.org/10.1016/j.agwat.2012.08.013

DeJonge, K. C., Kaleita, A. L., \& Thorp, K. R. (2007). Simulating the effects of spatially variable irrigation on corn yields, costs, and revenue in Iowa. Agric. Water Mgmt., 92(1), 99-109. http://dx.doi.org/10.1016/j.agwat.2007.05.008

Droogers, P. (2000). Estimating actual evapotranspiration using a detailed agro-hydrological model. J. Hydrol., 229(1-2), 50-58. 
http://dx.doi.org/10.1016/S0022-1694(99)00198-5

Evett, S. R., Howell Sr., T. A., Schneider, A. D., Copeland, K. S., Dusek, D. A., Brauer, D. K., ... Gowda, P. H. (2016). The Bushland weighing lysimeters: A quarter century of crop ET investigations to advance sustainable irrigation. Trans. ASABE, 59(1), 163-179. https://doi.org/10.13031/trans.59.11159

Farahani, H. J., Izzi, G., \& Oweis, T. Y. (2009). Parameterization and evaluation of the AquaCrop model for full and deficit irrigated cotton. Agron. J., 101(3), 469-476. https://doi.org/10.2134/agronj2008.0182s

Gee, G. W., \& Bauder, J. W. (1986). Particle size analysis. In Methods of soil analysis: Part 1. Physical and mineralogical methods (2nd ed., pp. 383-411). Agronomy Monograph No. 9. Madison, WI: ASA-SSSA.

Guerra, L. C., Garcia y Garcia, A., Hook, J. E., Harrison, K. A., Thomas, D. L., Stooksbury, D. E., \& Hoogenboom, G. (2007). Irrigation water use estimates based on crop simulation models and kriging. Agric. Water Mgmt., 89(3), 199-207. http://dx.doi.org/10.1016/j.agwat.2007.01.010

Guerra, L. C., Hoogenboom, G., Boken, V. K., Hook, J. E., Thomas, D. L., \& Harrison, K. A. (2004). Evaluation of the EPIC model for simulating crop yield and irrigation demand. Trans. ASAE, 47(6), 2091-2100. https://doi.org/10.13031/2013.17794

Hunsaker, D. J., \& Elshikha, D. M. (2017). Surface irrigation management for guayule rubber production in the U.S. desert southwest. Agric. Water Mgmt., 185, 43-57. https://doi.org/10.1016/j.agwat.2017.01.015

Hunsaker, D. J., Barnes, E. M., Clarke, T. R., Fitzgerald, G. J., \& Pinter Jr., P. J. (2005a). Cotton irrigation scheduling using remotely sensed and FAO-56 basal crop coefficients. Trans. ASAE, 48(4), 1395-1407. https://doi.org/10.13031/2013.19197

Hunsaker, D. J., Fitzgerald, G. J., French, A. N., Clarke, T. R., Ottman, M. J., \& Pinter Jr., P. J. (2007a). Wheat irrigation management using multispectral crop coefficients: I. Crop evapotranspiration prediction. Trans. ASABE, 50(6), 2017-2033. https://doi.org/10.13031/2013.24105

Hunsaker, D. J., Fitzgerald, G. J., French, A. N., Clarke, T. R., Ottman, M. J., \& Pinter Jr., P. J. (2007b). Wheat irrigation management using multispectral crop coefficients: II. Irrigation scheduling performance, grain yield, and water use efficiency. Trans. ASABE, 50(6), 2035-2050. https://doi.org/10.13031/2013.24106

Hunsaker, D. J., French, A. N., \& Thorp, K. R. (2013). Camelina water use and seed yield response to irrigation scheduling in an arid environment. Irrig. Sci., 31(5), 911-929. https://doi.org/10.1007/s00271-012-0368-7

Hunsaker, D. J., French, A. N., Waller, P. M., Bautista, E., Thorp, K. R., Bronson, K. F., \& Andrade-Sanchez, P. (2015). Comparison of traditional and ET-based irrigation scheduling of surface-irrigated cotton in the arid southwestern USA. Agric. Water Mgmt., 159, 209-224. http://dx.doi.org/10.1016/j.agwat.2015.06.016

Hunsaker, D. J., Pinter Jr., P. J., \& Cai, H. (2002). Alfalfa basal crop coefficients for FAO-56 procedures in the desert regions of the southwestern U.S. Trans. ASAE, 45(6), 1799-1815. https://doi.org/10.13031/2013.11431

Hunsaker, D. J., Pinter, P. J., \& Kimball, B. A. (2005b). Wheat basal crop coefficients determined by normalized difference vegetation index. Irrig. Sci., 24(1), 1-14. https://doi.org/10.1007/s00271-005-0001-0

Jensen, M. E., Allen, R. G., Howell, T. A., Martin, D. L., Snyder, R., \& Walter, I. A. (2016). Evaporation, evapotranspiration, and irrigation water requirements (2nd ed.). Reston, VA: ASCE Environmental and Water Resources Institute.

Jones, J. W., Hoogenboom, G., Porter, C. H., Boote, K. J.,
Batchelor, W. D., Hunt, L. A., ... Ritchie, J. T. (2003). The DSSAT cropping system model. European J. Agron., 18(3), 235-265. http://dx.doi.org/10.1016/S1161-0301(02)00107-7

Kisekka, I., Aguilar, J. P., Rogers, D. H., Holman, J., O’Brien, D. M., Klocke, N. (2016). Assessing deficit irrigation strategies for corn using simulation. Trans. ASABE, 59(1), 303-317. https://doi.org/10.13031/trans.59.11206

McCarthy, A. C., Hancock, N. H., \& Raine, S. R. (2013). Advanced process control of irrigation: The current state and an analysis to aid future development. Irrig. Sci., 31(3), 183-192. https://doi.org/10.1007/s00271-011-0313-1

McCarthy, A. C., Hancock, N. H., \& Raine, S. R. (2014). Simulation of irrigation control strategies for cotton using model predictive control within the VARIwise simulation framework. Comput. Electron. Agric., 101, 135-147. http://dx.doi.org/10.1016/j.compag.2013.12.004

McKinion, J. M., Baker, D. N., Whisler, F. D., \& Lambert, J. R. (1989). Application of the GOSSYM/COMAX system to cotton crop management. Agric. Syst., 31(1), 55-65. http://dx.doi.org/10.1016/0308-521X(89)90012-7

Meeks, C., Snider, J. L., Porter, W. M., Vellidis, G., Hawkins, G. L., \& Rowland, D. (2016). Primed acclimation: An assessment to improve water use efficiency in a sensor-based irrigation scheduling system. Proc. Beltwide Cotton Conf. Cordova, TN: National Cotton Council.

Modala, N. R., Ale, S., Rajan, N., Munster, C. L., DeLaune, P. B., Thorp, K. R., ... Barnes, E. M. (2015). Evaluation of the CSMCROPGRO-Cotton model for the Texas Rolling Plains region and simulation of deficit irrigation strategies for increasing water use efficiency. Trans. ASABE, 58(3), 685-696. https://doi.org/10.13031/trans.58.10833

Nair, S., Maas, S., Wang, C., \& Mauget, S. (2013). Optimal field partitioning for center-pivot-irrigated cotton in the Texas High Plains. Agron. J., 105(1), 124-133. https://doi.org/10.2134/agronj2012.0219

Post, D. F., Mack, C., Camp, P. D., \& Suliman, A. S. (1988). Mapping and characterization of the soils on the University of Arizona Maricopa Agricultural Center. Hydrology and Water Resources in Arizona and the Southwest, 18, 49-60. ArizonaNevada Academy of Science.

Richards, Q. D., Bange, M. P., \& Johnston, S. B. (2008). HydroLOGIC: An irrigation management system for Australian cotton. Agric. Syst., 98(1), 40-49. http://dx.doi.org/10.1016/j.agsy.2008.03.009

Sau, F., Boote, K. J., Bostick, W. M., Jones, J. W., \& Minquez, M. I. (2004). Testing and improving evapotranspiration and soil water balance of the DSSAT crop models. Agron. J., 96(5), 1243-1257. https://doi.org/10.2134/agronj2004.1243

Schaap, M. G., Leij, F. J., \& van Genuchten, M. T. (2001). Rosetta: A computer program for estimating soil hydraulic parameters with hierarchical pedotransfer functions. J. Hydrol., 251(3-4), 163-176. http://dx.doi.org/10.1016/S0022-1694(01)00466-8

Sobol, I. M. (1998). On quasi-Monte Carlo integrations. Math. Comput. Simul., 47(2), 103-112. http://dx.doi.org/10.1016/S0378-4754(98)00096-2

Suleiman, A. A., Tojo Soler, C. M., \& Hoogenboom, G. (2007). Evaluation of FAO-56 crop coefficient procedures for deficit irrigation management of cotton in a humid climate. Agric. Water Mgmt., 91(1-3), 33-42. http://dx.doi.org/10.1016/j.agwat.2007.03.006

Thorp, K. R., Ale, S., Bange, M. P., Barnes, E. M., Hoogenboom, G., Lascano, R. J., ... White, J. W. (2014a). Development and application of process-based simulation models for cotton production: A review of past, present, and future directions. $J$. Cotton Sci., 18(1), 10-47.

Thorp, K. R., Barnes, E. M., Hunsaker, D. J., Kimball, B. A., White, 
J. W., Nazareth, V. J., \& Hoogenboom, G. (2014b). Evaluation of CSM-CROPGRO-Cotton for simulating effects of management and climate change on cotton growth and evapotranspiration in an arid environment. Trans. ASABE, 57(6), 1627-1642. https://doi.org/10.13031/trans.57.10612

Thorp, K. R., Hunsaker, D. J., French, A. N., Bautista, E., \& Bronson, K. F. (2015). Integrating geospatial data and cropping system simulation within a geographic information system to analyze spatial seed cotton yield, water use, and irrigation requirements. Prec. Agric., 16(5), 532-557. https://doi.org/10.1007/s11119-015-9393-x

Thorp, K. R., Hunsaker, D. J., French, A. N., White, J. W., Clarke,
T. R., \& Pinter Jr., P. J. (2010). Evaluation of the CSMCROPSIM-CERES-Wheat model as a tool for crop water management. Trans. ASABE, 53(1), 87-102. https://doi.org/10.13031/2013.29505

Walter, I. A., Allen, R. G., Elliott, R., Itenfisu, D., Brown, P., Jensen, M. E., ... Wright, J. L. (2005). The ASCE standardized reference evapotranspiration equation. Reston, VA: ASCE Environmental and Water Resources Institute.

Yang, Y., Yang, Y., Moiwo, J. P., \& Hu, Y. (2010). Estimation of irrigation requirement for sustainable water resources reallocation in North China. Agric. Water Mgmt., 97(11), 17111721. http://dx.doi.org/10.1016/j.agwat.2010.06.002 